\title{
Iron oxide nanoparticles modulate lipopolysaccharide-induced inflammatory responses in primary human monocytes
}

This article was published in the following Dove Press journal:

International Journal of Nanomedicine

13 September 2016

Number of times this article has been viewed

\author{
Susann Grosse' \\ Jørgen Stenvik ${ }^{1,2}$ \\ Asbjørn M Nilsen' \\ 'Department of Cancer Research \\ and Molecular Medicine, ${ }^{2}$ Centre of \\ Molecular Inflammation Research, \\ Norwegian University of Science and \\ Technology, Trondheim, Norway
}

\begin{abstract}
Co-stimulation of the immune system to more than one agent concomitantly is very common in real life, and considering the increasing use of engineered nanoparticles and nanomaterials, it is highly relevant to assess the ability of these materials to modulate key innate immune responses, which has not yet been studied in detail. We investigated the immunomodulatory effects of $10 \mathrm{~nm}$ and $30 \mathrm{~nm}$ iron oxide nanoparticles (IONPs) on primary human monocytes in the presence and absence of Toll-like receptor 4 agonist lipopolysaccharide (LPS). Prior to the cell studies, we characterized the physicochemical properties of the nanoparticles in cell culture medium and ensured that the nanoparticles were free from biological contamination. Cellular uptake of the IONPs in monocytes was assessed using transmission electron microscopy. Using enzyme-linked immunosorbent assay, we found that the IONPs per se did not induce the production of proinflammatory cytokines tumor necrosis factor- $\alpha$, interleukin- 6 , and interleukin- $1 \beta$. However, the IONPs had the ability to suppress LPS-induced nuclear factor kappa B activation and production of proinflammatory cytokines in primary human monocytes in an LPS and a particle dose-dependent manner. Using confocal microscopy and fluorescently labeled LPS, we showed that the effects correlated with impaired LPS internalization by monocytes in the presence of IONPs, which could be partly explained by LPS adsorption onto the nanoparticle surface. Additionally, the results from particle pretreatment experiments indicate that other cellular mechanisms might also play a role in the observed effects, which warrants further studies to elucidate the additional mechanisms underlying the capacity of IONPs to alter the reactivity of monocytes to LPS and to mount an appropriate cellular response.
\end{abstract}

Keywords: iron oxide nanoparticles, primary human monocytes, PBMCs, cytokines, LPS adsorption, Toll-like receptors

\section{Introduction}

Due to the unique physical and chemical properties compared to the bulk material, nanomaterials are very attractive for a wide range of applications, including biomedical applications. ${ }^{1}$ Assessing the interactions of engineered nanomaterials with cells of the immune system, especially the innate immune system, is an important part in nanotoxicology, which has not received enough attention. The innate immune system plays a vital role in the recognition and clearance of endogenous and exogenous danger and damage. The sensing of pathogen-associated molecular patterns (PAMPs) is mediated by pattern recognition receptors, of which the Toll-like receptors (TLRs) are the best characterized. ${ }^{2}$ Among others, these receptors are expressed on macrophages, which constantly monitor the surroundings for danger signals. The activation of macrophage TLRs by PAMPs elicits proinflammatory responses in these cells, which subsequently
Correspondence: Susann Grosse Department of Cancer Research and Molecular Medicine, Norwegian University of Science and Technology, N-749I Trondheim, Norway

Tel +4740332006

Email susann.grosse@ntnu.no 
activates other immune and nonimmune cells, resulting in tissue inflammation. The well-studied PAMP lipopolysaccharide (LPS) is recognized by TLR4 and induces the activation of two signaling pathways that result in the production of proinflammatory cytokines such as tumor necrosis factor- $\alpha$ (TNF $\alpha$ ) and interleukin (IL)-1 $\beta$ via activation of the transcription factor nuclear factor kappa $\mathrm{B}(\mathrm{NF} \kappa \mathrm{B})$ and interferon $\beta$ (IFN $\beta$ ) via activation of the transcription factor interferon regulatory factor 3 .

Immunological studies are particularly needed for nanomaterials that are intended to be used in biomedical applications, as these materials are often injected into the blood stream and thus come in direct contact with various immune cells. ${ }^{3}$ Due to their magnetic properties, iron oxide nanoparticles (IONPs) are widely used in biomedical applications, such as contrast agents for magnetic resonance imaging, in targeted drug delivery, and for induced hyperthermia cancer treatment. ${ }^{4}$ Despite the use of IONPs in these applications, there are ongoing concerns regarding their potential impact on human health and the immune system. Previous studies illustrated that IONPs can induce reactive oxygen species, mitochondrial damage, and autophagy in lung epithelial cells ${ }^{5}$ and may impair the cytoskeleton in growing neurons. ${ }^{6}$ In contrast, another study reported that IONPs had no effects on cell viability. ${ }^{7}$ These contradictory results are likely to be due to the use of IONPs with various physicochemical properties, different cell types, and experimental conditions such as cell number and serum concentration in cell culture medium. ${ }^{8}$

Nanomaterials can interact with immune cells and either stimulate or suppress immune responses. ${ }^{9,10}$ Moreover, particle characteristics, such as size, shape, and surface properties, determine the immunotoxicity of these materials. For example, Sahu et $\mathrm{al}^{11}$ showed that $\mathrm{Zn}$ oxide nanoparticles had a higher potential to induce inflammatory cytokines than microsized $\mathrm{Zn}$ oxide particles in human monocyte-like THP-1 cells. Another study found that surface-modified silica nanoparticles could suppress inflammatory responses compared to unmodified silica nanoparticles. ${ }^{12}$

However, detailed research on the immunomodulatory properties of engineered nanoparticles is still lacking, especially concerning the exposure of the immune system to more than one stimulus concomitantly, which is the rule in real life. Co-stimulation of nanoparticles with PAMPs could potentially alter the reactivity of immune cells to respond to danger signals and alter the defensive response, which might result in either inadequate capacity of eliminating dangerous PAMPs or in an exaggerated reaction leading to shock or chronic inflammation. Results from previous studies suggest that individuals with preexisting inflammatory conditions are more prone to adverse effects of engineered nanomaterials. Studies by Inoue and Takano ${ }^{13}$ and Inoue et $\mathrm{al}^{14}$ demonstrated that exposure to particulate air pollution and engineered nanoparticles can aggravate preexisting pulmonary inflammation in mice. Similarly, it has been shown that carbon nanotubes can promote allergic immune responses in mice. ${ }^{15} \mathrm{~A}$ study by Laverny et $\mathrm{al}^{16}$ demonstrated that the LPS-induced TNF $\alpha$, IL-6, and IL-12 response was increased by multiwalled carbon nanotubes in peripheral blood mononuclear cells (PBMCs) from healthy donors. In contrast, there have also been a few studies demonstrating a reduction in LPS-induced cytokine production by engineered nanoparticles. ${ }^{17-19}$

The aim of this study was to investigate the immunomodulatory effects of IONPs in the presence and absence of the TLR4 agonist LPS in primary human monocytes and the underlying mechanism(s) of action.

\section{Materials and methods Nanoparticle suspensions}

The 10-nm- and 30-nm-sized IONPs (catalog numbers SHP-10-10 and SXP-30-10, respectively) were purchased from Ocean NanoTech, LLC (San Diego, CA, USA). These particles are coated with organic layers consisting of a monolayer of oleic acid and a monolayer of amphiphilic polymer. Their reactive group is carboxylic acid.

\section{Characterization of IONPs}

The size and shape of the $10 \mathrm{~nm}$ and $30 \mathrm{~nm}$ IONPs were assessed by transmission electron microscopy (TEM) using a JEOL TEM (JEOL, Tokyo, Japan) at $80 \mathrm{kV}$. Formvar coated grids were placed on $50 \mu \mathrm{L}$ drops of the IONP samples $(0.5 \mathrm{mg} / \mathrm{mL})$ for 5 minutes. The grids were gently drained with filter paper and subsequently inspected without further treatment. The average hydrodynamic diameter, polydispersity index, and zeta potential of the IONPs in water (as delivered) and cell culture medium (RPMI 1640 supplemented with $5 \%$ pooled human A+ serum) were determined using dynamic light scattering (Malvern Zetasizer Nano-ZS; Malvern Instruments, Malvern, UK) at $25^{\circ} \mathrm{C}$, with a scattering angle of $173^{\circ}$ and nanoparticles at final concentrations of $100 \mu \mathrm{g} / \mathrm{mL}$ and $500 \mu \mathrm{g} / \mathrm{mL}$. For the measurement of the zeta potential, a suspension of IONPs $(500 \mu \mathrm{g} / \mathrm{mL})$ was transferred into a $1 \mathrm{~mL}$ zeta potential cuvette (DTS1060; Malvern Instruments), and the electrophoretic mobility of the sample was measured at $25^{\circ} \mathrm{C}$. The chemical composition of the inorganic core of the IONPs was determined 
using X-ray diffraction. Sample dispersions were sealed in glass capillaries, and diffraction data were collected using a Bruker D8 Advance A25 powder diffractometer, utilizing Mo K-alpha radiation and running in focusing transmission geometry. The phases present were identified via reference to the ICCD PDF4+ crystal structure database.

\section{Biological contamination}

The Limulus Amebocyte Lysate (LAL) assay is frequently used for the detection of endotoxin in biological samples. However, the IONPs interfered with the QCL-1000 chromogenic LAL assay (catalog number 50-647U; Lonza, Basel, Switzerland). Thus, possible contamination with TLR2 and TLR4 agonists was assessed with a luciferase reporter cell assay. Briefly, human embryonic kidney (HEK293) cells were maintained in RPMI 1640 medium (supplemented with $10 \%$ fetal calf serum, $0.1 \%$ ciprofloxacin, and $2 \mathrm{mM}$ glutamine) at $37^{\circ} \mathrm{C}$ and $5 \% \mathrm{CO}_{2}$. The cells were transfected with a Firefly luciferase NFKB-reporter plasmid (ELAM-luc) together with either vector only (TLR-), TLR2+/CD14, or TLR4+/MD2+/CD14 plasmids and incubated for 24 hours at $37^{\circ} \mathrm{C}$ and $5 \% \mathrm{CO}_{2}$. The cells were cotransfected with a pRL-null control reporter vector, which provides constitutive expression of Renilla luciferase. Following transfection, the cells were treated with IONPs $(1 \mu \mathrm{g} / \mathrm{mL}, 10 \mu \mathrm{g} / \mathrm{mL}$, and $100 \mu \mathrm{g} / \mathrm{mL})$ for further 24 hours. LPS (100 ng/mL; ultrapure LPS from Escherichia coli Serotype 0111:B4; InvivoGen, San Diego, CA, USA) and fibroblast-stimulating lipopeptide 1 (100 ng/mL; EMC, Tübingen, Germany) were included as positive controls for the activation of TLR4 and TLR2, respectively. After incubation, the cells were lysed with passive lysis buffer (catalog number E1941; Promega Corporation, Fitchburg, WI, USA). Luciferase substrate was added, and the luminescence of the cell lysate was detected using a plate reader (Victor ${ }^{3} 1420$ Multilabel Counter, PerkinElmer ${ }^{\mathrm{TM}}$; PerkinElmer Inc., Waltham, MA, USA).

\section{Isolation of primary human PBMCs and monocytes}

PBMCs were isolated from Lymphoprep (Axis-Shield, Oslo, Norway) separated fresh or day-old buffy coats (Blood Bank, St Olav's Hospital, Trondheim, Norway) and cultivated in RPMI 1640 supplemented with 5\% pooled human A+ serum. The cells were seeded at $4 \times 10^{6} / \mathrm{mL}$ in 24 -well plates $(0.5 \mathrm{~mL} /$ well $)$ and allowed to adhere for 90 minutes at $37^{\circ} \mathrm{C}$ and $5 \% \mathrm{CO}_{2}$. In order to remove nonadherent cells, the wells were washed three times with prewarmed $\left(37^{\circ} \mathrm{C}\right)$ Hank's balanced salt solution. The primary monocytes, which adhered to the plastic of the well plate, were stimulated with IONPs ( $1 \mu \mathrm{g} / \mathrm{mL}, 10 \mu \mathrm{g} / \mathrm{mL}$, and $100 \mu \mathrm{g} / \mathrm{mL})$ in RPMI $1640 / 5 \% \mathrm{~A}+$ serum or in combination with LPS $(0.5 \mathrm{ng} / \mathrm{mL}, 10 \mathrm{ng} / \mathrm{mL}$, $50 \mathrm{ng} / \mathrm{mL}, 100 \mathrm{ng} / \mathrm{mL}, 500 \mathrm{ng} / \mathrm{mL}$, and 1,000 ng/mL) for 6 hours. In another set of experiments, nonadherent PBMCs and magnetic bead-purified (pan-monocyte isolation kit; Miltenyi Biotec, Bergisch Gladbach, Germany) nonadherent monocytes from buffy coats were stimulated with IONPs and LPS. Furthermore, primary human monocytes were cultured in RPMI 1640 medium containing different serum concentrations $(5 \%, 10 \%$, and 20\% A+ serum).

Additionally, pretreatment experiments were conducted. Monocytes were pretreated with $10 \mathrm{~nm}$ IONPs $(1 \mu \mathrm{g} / \mathrm{mL}$, $10 \mu \mathrm{g} / \mathrm{mL}$, and $100 \mu \mathrm{g} / \mathrm{mL}$ ) for 3 hours, washed three times with prewarmed $\left(37^{\circ} \mathrm{C}\right)$ Hank's solution, and were then treated with LPS $(0.5 \mathrm{ng} / \mathrm{mL})$ for 6 hours.

\section{Cell viability}

The alamarBlue assay was used to assess the viability of monocytes after treatment with IONPs alone or in combination with LPS $(0.5 \mathrm{ng} / \mathrm{mL})$. After 5 hours of stimulation, alamarBlue reagent (catalog number DAL1100; Thermo Fisher Scientific, Waltham, MA, USA) was added directly to the wells of a 24-well plate. The cells were incubated for further 12 hours. The color of the media surrounding viable cells changes from nonfluorescent blue (resazurin) to highly fluorescent red (resorufin) in this assay. Fluorescence was measured at an excitation wavelength of $531 \mathrm{~nm}$ and emission of $590 \mathrm{~nm}$ using a plate reader $\left(\right.$ Victor $^{3} 1420$ Multilabel Counter, PerkinElmer ${ }^{\mathrm{TM}}$ ), and viability was calculated as $\%$ viability compared to control medium.

\section{Cytokine analysis}

After 6 hours, the plates were centrifuged at $470 \times g$ for 10 minutes, and the supernatant was frozen at $-20^{\circ} \mathrm{C}$ until cytokine analysis. The levels of the proinflammatory cytokines TNF $\alpha$, IL-6, and IL- $1 \beta$ in the monocyte supernatants were detected using enzyme-linked immunosorbent assay (ELISA) (R\&D Systems, Inc., Minneapolis, MN, USA [TNF $\alpha$ and IL-6] and BD Biosciences, San Jose, CA, USA [IL-1 $\beta])$.

\section{Cytokine adsorption onto the nanoparticle surface}

Cytokine adsorption experiments were performed according to a previously described method. ${ }^{20}$ Briefly, in a cell-free system, IONPs at $1 \mu \mathrm{g} / \mathrm{mL}, 10 \mu \mathrm{g} / \mathrm{mL}$, and $100 \mu \mathrm{g} / \mathrm{mL}$ were incubated with twofold serial dilutions of either TNF $\alpha$ 
(0-1,000 pg/mL), IL-6 (0-600 pg/mL), or IL-1 $\beta$-standard $(0-250 \mathrm{pg} / \mathrm{mL})$ in 96 -well plates for 6 hours at $37^{\circ} \mathrm{C}$ and $5 \%$ $\mathrm{CO}_{2}$. These conditions were selected to mimic the exposure scenario from the monocyte experiments. Following incubation, the plates were centrifuged at $470 \times g$ for 10 minutes, and the supernatant was frozen at $-20^{\circ} \mathrm{C}$ until cytokine analysis.

\section{Transmission electron microscopy}

Primary human monocytes were stimulated with $100 \mu \mathrm{g} / \mathrm{mL}$ IONPs for 2 hours and fixed with 2.5\% glutaraldehyde and $2 \%$ paraformaldehyde in $0.1 \mathrm{M}$ phosphate buffer ( $\mathrm{pH} 7.2$ ). Postfixation was done in $2 \%$ osmium tetroxide. The cells were dehydrated in a graded series of alcohol and embedded in epoxy resin. Ultrathin sections $(60 \mathrm{~nm})$ were collected on grids, stained with uranyl acetate (15 minutes) and lead citrate (5 minutes), and observed by TEM using a JEOL JEM 1011 microscope operated at $80 \mathrm{keV}$. Image acquisition was done with a Morada CCD camera.

\section{Quantitative real-time polymerase chain reaction}

Total RNA (DNase treated) from primary human monocytes was extracted using an RNeasy Mini kit (Qiagen NV, Venlo, the Netherlands) and the QIAcube robotic work station (Qiagen NV), following the manufacturer's instruction. Reverse transcription of RNA to complementary DNA was performed using a high-capacity RNA-to-cDNA kit (Thermo Fisher Scientific), and the concentration and purity of the RNA were determined using NanoDrop (Thermo Fisher Scientific). Perfecta qPCR FastMix ${ }^{\text {TM }}$ (Quanta) and the following TaqMan probes (Thermo Fisher Scientific) were used: TNF $\alpha$ (Hs00174128_m1), IL-6 (Hs00985639_m1), IL-1 $\beta$ (Hs01555410_m1), IFNß1 (Hs01077958_s1), and TBP (Hs 00427620_m1). Triplicate samples were run as singlets in polymerase chain reaction, and all data were normalized to TBP. Relative gene expression was calculated as fold induction over control, using the StepOne software Version 2.1 (Thermo Fisher Scientific).

\section{Fluorescence microscopy}

In order to evaluate if the IONPs reduce the uptake of LPS in the cells, primary monocytes were incubated with IONPs (1 $\mu \mathrm{g} / \mathrm{mL}, 10 \mu \mathrm{g} / \mathrm{mL}$, and $100 \mu \mathrm{g} / \mathrm{mL}$ ) and $100 \mathrm{ng} / \mathrm{mL}$ Alexa594-labeled LPS (E. coli Serotype O55:B5; Thermo Fisher Scientific). Cell culture medium and LPS (100 ng/mL) served as negative and positive controls, respectively. Following stimulation, the exposure solution was removed, and the cells were fixed with $4 \%$ paraformaldehyde for
10 minutes at room temperature. After a washing step, the cells were incubated with an autofluorescence quenching solution $\left(\mathrm{NH}_{4} \mathrm{Cl}\right)$ for further 10 minutes, before the DNA was stained with DraQ5 (concentration $5 \mu \mathrm{M}$ ), a far-red DNA staining (Cell Signaling Technology, Danvers, MA, USA). The samples were analyzed semiquantitatively using a Leica SP8 confocal laser microscope equipped with a $63 \times / 1.4$ oilimmersion objective. All images were taken with the same adjustments (ie, zoom factor and intensity range).

\section{LPS adsorption to the nanoparticles}

In order to investigate if LPS adsorbs onto the surface of the IONPs, centrifugation experiments were performed. Cell-free samples $(1 \mathrm{~mL})$ containing both nanoparticles $(1 \mu \mathrm{g} / \mathrm{mL}, 10 \mu \mathrm{g} / \mathrm{mL}$, and $100 \mu \mathrm{g} / \mathrm{mL})$ and LPS $(0.5 \mathrm{ng} / \mathrm{mL}$ and $100 \mathrm{ng} / \mathrm{mL}$ in two different setups) were incubated for 10 minutes at room temperature and subsequently centrifuged at $15,000 \times g$ for 2 hours $\left(4^{\circ} \mathrm{C}\right)$. Cell culture medium and LPS $(0.5 \mathrm{ng} / \mathrm{mL}$ and $100 \mathrm{ng} / \mathrm{mL})$ served as negative and positive controls, respectively. UV-vis absorbance at $280 \mathrm{~nm}$ before and after centrifugation was measured to verify that the samples were free of nanoparticles after the centrifugation. Following centrifugation, the supernatants $(1 \mathrm{~mL})$ were sampled. Additionally, the pellets containing the nanoparticles and possibly bound LPS were resuspended in $1 \mathrm{~mL}$ cell culture medium to achieve a similar end concentration as in the original solutions. Both the supernatants and the resuspended pellets were added to primary human monocytes. Following 6 hours incubation, the plates with the cells were centrifuged at $470 \times g$ for 10 minutes, and the supernatants were frozen at $-20^{\circ} \mathrm{C}$ until cytokine analysis. In order to show the LPS adsorption to the IONPs more directly, cellfree samples containing nanoparticles $(100 \mu \mathrm{g} / \mathrm{mL})$ and LPS (100 ng/mL and $500 \mathrm{ng} / \mathrm{mL}$ in two different setups) were centrifuged at $15,000 \times g$ for 2 hours $\left(4^{\circ} \mathrm{C}\right)$. The fluorescence intensity of the resuspended pellets was compared to a sample containing only nanoparticles $(100 \mu \mathrm{g} / \mathrm{mL})$. Images of five different fields per sample were collected using the Leica SP8 confocal microscope as described earlier.

\section{Statistical analysis}

Statistical analysis was done with GraphPad Prism 6 (GraphPad Software, Inc., La Jolla, CA, USA). The data were analyzed using one-way, repeated measures analysis of variance and two-way analysis of variance with Dunnett's multiple comparison test, where appropriate. In order to eliminate uncertainties concerning normal distribution of the data due to a low sample number between three and nine, 
the data were log-transformed before analysis. Results were considered statistically significant when $P<0.05$.

\section{Ethics}

The use of human monocytes in our experiments was approved by the Regional Committee for Medical and Health Research Ethics in Central Norway (REC Central), The Norwegian Ministry of Education and Research, 2009/2245. Experiments were conducted according to their regulations and guidelines.

\section{Results}

\section{Physicochemical characterization of the IONPs}

A schematic of the IONPs is shown in Figure 1. The hydrodynamic size of the $10 \mathrm{~nm}$ and $30 \mathrm{~nm}$ particles in water was slightly different from the particle core size obtained by TEM, as these particles are coated with a polymer (Table 1). In RPMI 1640 medium supplemented with 5\% pooled A+ serum, the $10 \mathrm{~nm}$ and $30 \mathrm{~nm}$ nanoparticles formed stable, nanometer-sized agglomerates (122 nm and $84 \mathrm{~nm}$, respectively). Using X-ray diffraction, the core of the $10 \mathrm{~nm}$ particles was determined to be $\mathrm{Fe}_{2} \mathrm{O}_{3}$ and the core of the $30 \mathrm{~nm}$ particles was $\mathrm{Fe}_{3} \mathrm{O}_{4}$ (Table 1). The zeta potential in water was not markedly different between the two IONPs tested. Both types of nanoparticles showed a high negative zeta potential in water, indicating good particle stability. The zeta potential decreased in RPMI 1640 medium with 5\% A+ serum, indicating reduced particle stability (Table 1). The shape of the IONPs was determined by TEM, demonstrating that the $10 \mathrm{~nm}$ and $30 \mathrm{~nm}$ nanoparticles were spherical (Figure 1).

\section{Biological contamination}

A TLR2-NFKB and TLR4-NFKB reporter cell assay was used to test the IONPs for biological contamination. None of the IONPs alone activated TLR2 or TLR4 in transfected HEK293 cells, which indicates that the particles were not contaminated with TLR2 or TLR4 agonists (Figure S1).

\section{Primary human monocytes and PBMCs Cellular uptake of IONPs}

To evaluate cellular uptake of the IONPs, primary human monocytes were studied by TEM (Figure 2). Both nanoparticle types were taken up by the cells in membrane-bound compartments, likely endosomes or lysosomes. However, it seemed that a larger number of $10 \mathrm{~nm}$ particles were taken up compared to the $30 \mathrm{~nm}$ particles (Figure 2).

\section{Cytokine adsorption onto the nanoparticle surface}

In order to correctly interpret the ELISA readouts for the cytokine production that was used as a major end point in this study, nanoparticle interference with the cytokine measurements, that is, by adsorption of the cytokines onto the particle surface, was determined. Our results show that neither the $10 \mathrm{~nm}$ nor the $30 \mathrm{~nm}$ IONPs affected the analysis of TNF $\alpha$ and IL-1 $\beta$ (Figure S2). However, in contrast to the $30 \mathrm{~nm}$ IONPs, we observed that the $10 \mathrm{~nm}$ particles (at $100 \mu \mathrm{g} / \mathrm{mL}$ ) reduced the signal in the IL-6 ELISA, possibly via adsorption of IL-6 (Figure S2). Thus, the IL-6 values for the highest particle concentration were corrected as described by Herseth et al. ${ }^{21}$

\section{Stimulation of monocytes with IONPs in the absence and presence of LPS}

The stimulation of primary human monocytes with the $10 \mathrm{~nm}$ and $30 \mathrm{~nm}$ IONPs alone did not result in increased TNF $\alpha$ release from the cells (Figure 3A). Similar results were found for IL-6 and IL-1 $\beta$ production (Figure 3A). Furthermore, none of the IONPs alone significantly affected viability, although a tendency for reduction in viability (15\%) was
A

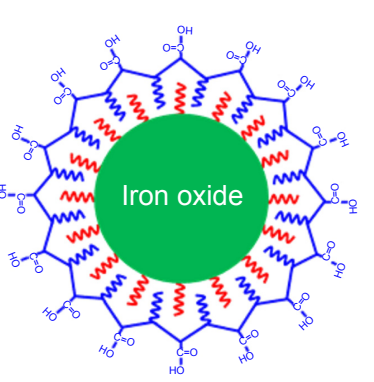

B

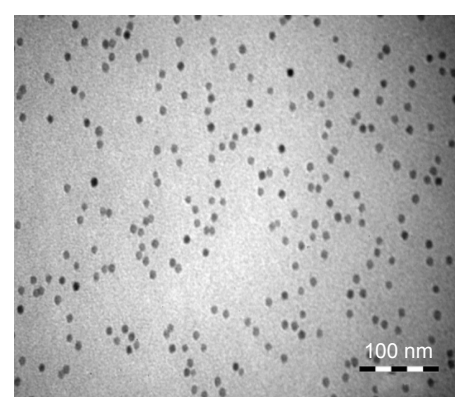

\section{C}

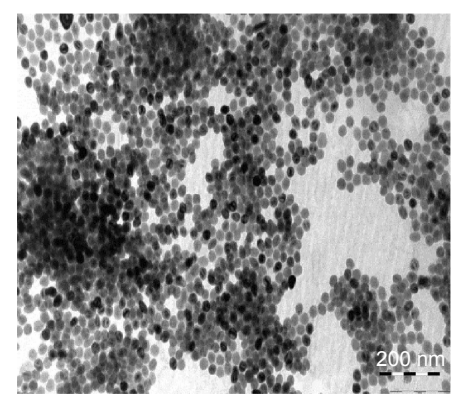

Figure I Physicochemical properties of IONPs.

Notes: (A) Schematic drawing of the IONPs coated with a monolayer of oleic acid and a monolayer of amphiphilic polymer. The reactive group on the surface is carboxylic acid. (B) TEM image of the $10 \mathrm{~nm}$ IONPs. (C) TEM image of the $30 \mathrm{~nm}$ IONPs.

Abbreviations: IONPs, iron oxide nanoparticles; TEM, transmission electron microscopy. 
Table I Physicochemical characterization of the iron oxide nanoparticles

\begin{tabular}{|c|c|c|c|c|c|}
\hline \multirow[t]{2}{*}{ IONPs } & \multicolumn{2}{|c|}{ Hydrodynamic diameter (nm) (PDI) } & \multicolumn{2}{|l|}{ Zeta potential $(\mathrm{mV})$} & \multirow{2}{*}{$\begin{array}{l}\text { Chemical } \\
\text { composition }\end{array}$} \\
\hline & Water (as supplied) & RPMI 1640/5\% A+ serum ${ }^{a}$ & Water (as supplied) & RPMI I640/5\% A+ serum & \\
\hline $10 \mathrm{~nm}$ & $21.2 \pm 0.1(0.133)$ & $\mid 28.7 \pm 0.8(0.23 \mid)$ & -53.3 & -24.9 & $\mathrm{Fe}_{2} \mathrm{O}_{3}$ \\
\hline $30 \mathrm{~nm}$ & $43.0 \pm 0.2(0.088)$ & $84 \pm 1.2(0.199)$ & -48.0 & -9.5 & $\mathrm{Fe}_{3} \mathrm{O}_{4}$ \\
\hline
\end{tabular}

Notes: Average values from six measurements \pm SD are shown. ${ }^{a} A+$ serum: pooled human serum, blood type $A+$.

Abbreviations: IONPs, iron oxide nanoparticles; PDI, polydispersity index.

seen with the highest concentration of the $30 \mathrm{~nm}$ particles (Figure 3B).

To further evaluate the immune regulation of the IONPs, we co-stimulated the cells with nanoparticles and LPS (Figure 4A). Co-stimulation of the monocytes with different concentrations of $10 \mathrm{~nm}$ and $30 \mathrm{~nm}$ IONPs and LPS $(0.5 \mathrm{ng} / \mathrm{mL})$ led to a significant inhibition of the TNF $\alpha$, IL-1 $\beta$, and IL-6 response induced by LPS, with the $10 \mathrm{~nm}$ particles showing the most potent effect. The LPS-induced cytokine production was completely inhibited in the presence of IONPs at $10 \mu \mathrm{g} / \mathrm{mL}$ and $100 \mu \mathrm{g} / \mathrm{mL}$. However, the viability was not significantly affected by the cell treatment with nanoparticles and LPS (Figure 4B).

To further explore the observed effects, all additional experiments were conducted using only the $10 \mathrm{~nm}$ IONPs as they gave the most pronounced effect. The results from additional control experiments showed that cellular adherence to the plastic of the well plate had no influence on the observed cytokine response, as nonadherent monocytes (Figure S3A) showed the same cytokine response to stimulation with $10 \mathrm{~nm}$ IONPs and LPS as the adherent monocytes (Figure 4A). Additionally, similar results were seen with PBMCs co-stimulated with IONPs and LPS (Figure S3B). Thus, the cytokine response from the monocytes is neither influenced by the presence of lymphocytes in these experiments nor the monocyte adherence to a plastic surface.

As we cultured the monocytes in medium with low serum concentration ( $5 \% \mathrm{~A}+$ serum), we were interested to evaluate if a higher serum concentration in the cell culture medium
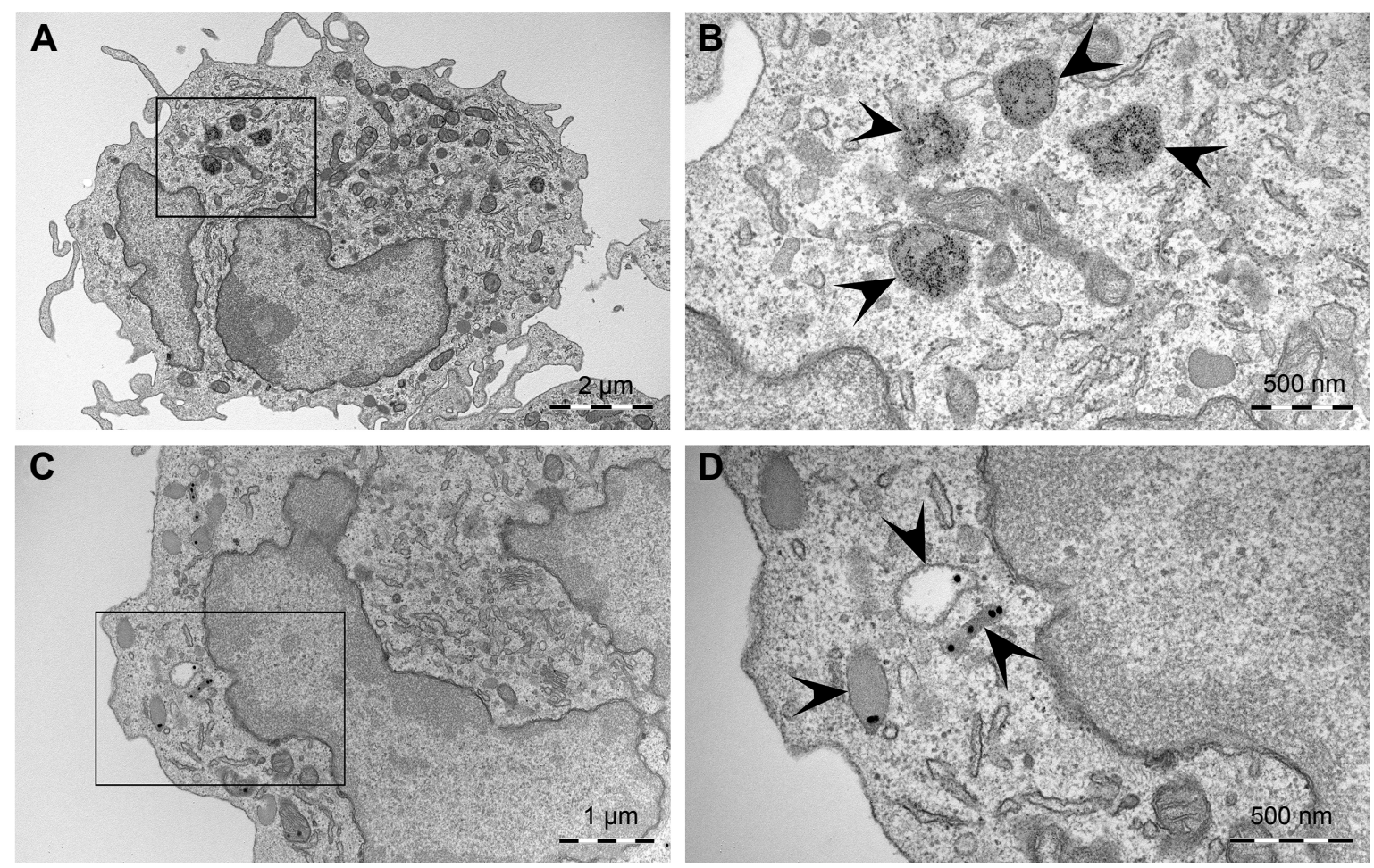

Figure 2 Transmission electron microscopic analysis of IONPs-treated primary human monocytes.

Notes: The cells were treated with (A) $10 \mathrm{~nm}$ IONPs and (C) $30 \mathrm{~nm}$ IONPs for 2 hours, and particle uptake was evaluated. (B) $10 \mathrm{~nm} 10 \mathrm{NPs}$; magnification of the marked area in (A). (D) $30 \mathrm{~nm}$ IONPs; magnification of the marked area in (C). Black arrow heads indicate the membrane-bound compartments containing the IONPs. Abbreviation: IONPs, iron oxide nanoparticles. 
A
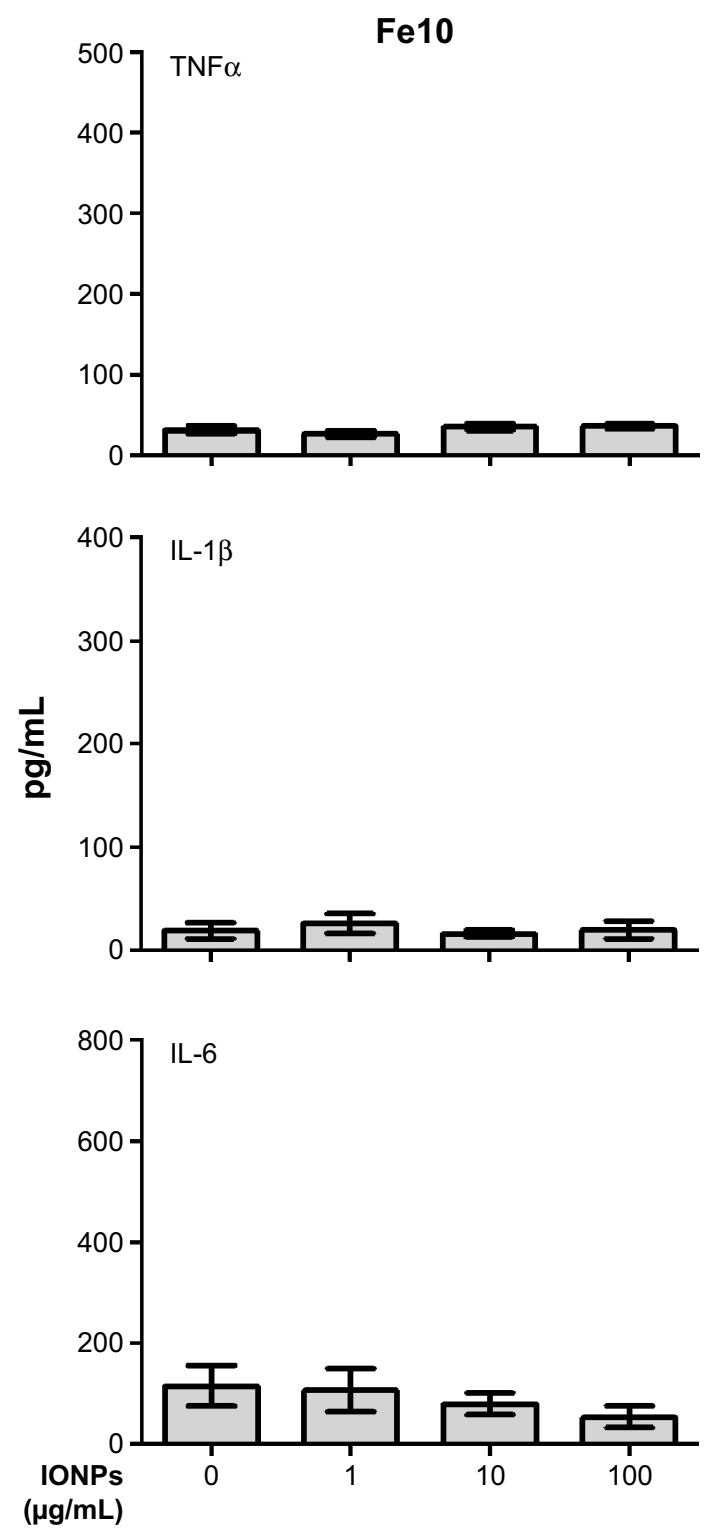

B

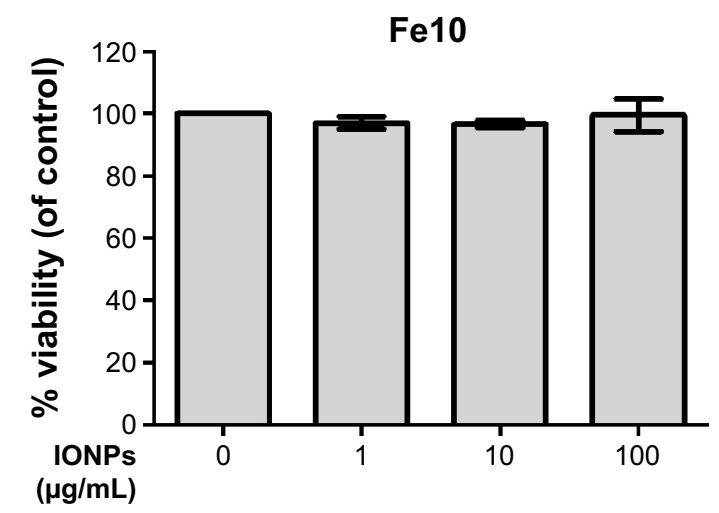

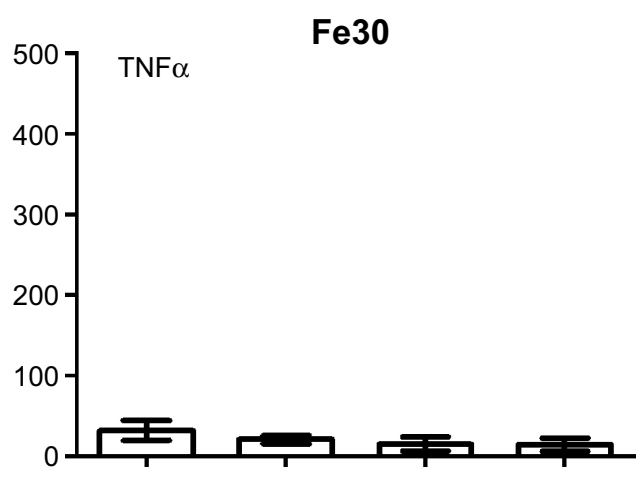
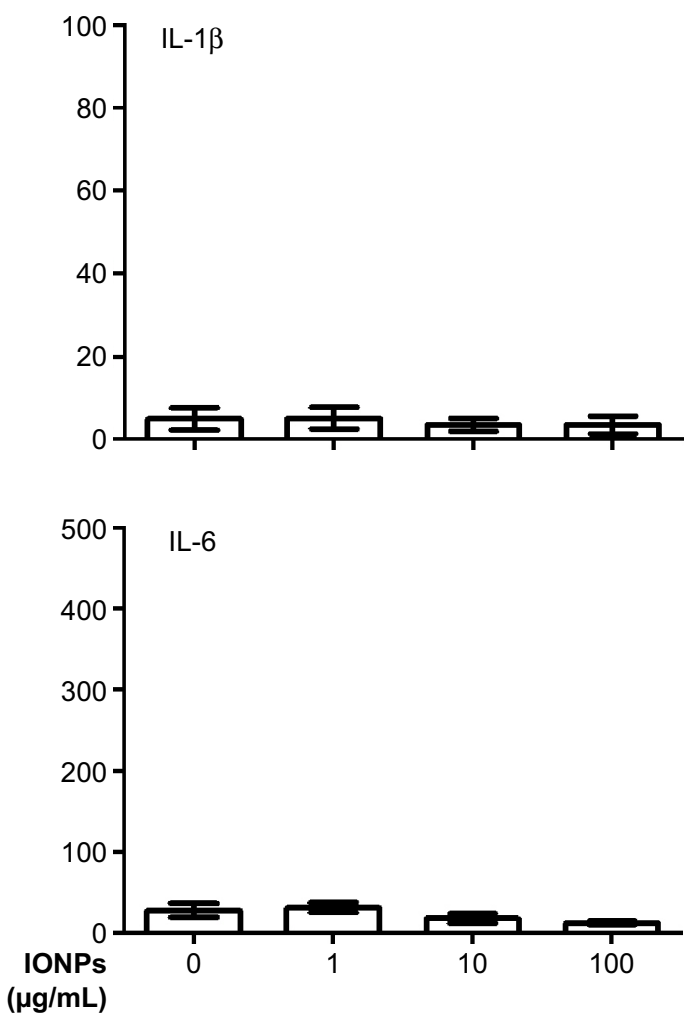

$(\mu \mathrm{g} / \mathrm{mL})$

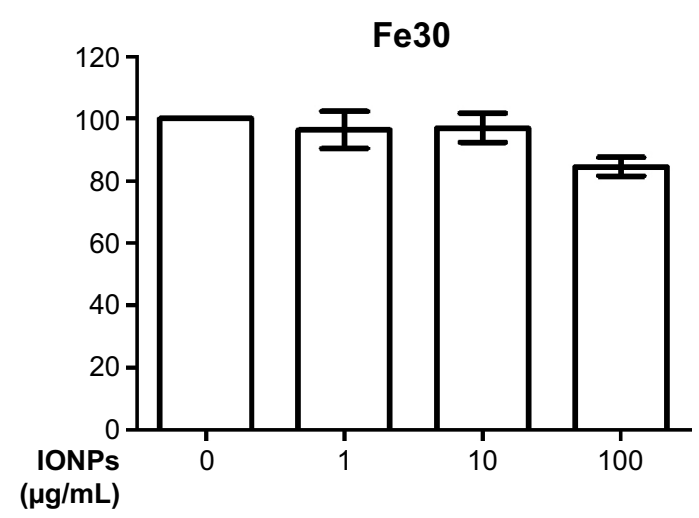

Figure 3 Cytokine response and viability in iron oxide-treated primary human monocytes.

Notes: The cells were treated with IONPs $(1 \mu \mathrm{g} / \mathrm{mL}, 10 \mu \mathrm{g} / \mathrm{mL}$, and $100 \mu \mathrm{g} / \mathrm{mL})$ in RPMI $1640 / 5 \%$ A+ serum for 6 hours. The cytokine concentration released into the medium (A) was measured using ELISA, and the monocyte viability (B) was determined with the alamarBlue assay. Results are expressed as mean \pm SEM; $n=3-7$ for TNF $\alpha$, IL-6, and IL-I $\beta$, and $n=2$ for viability.

Abbreviations: IONPs, iron oxide nanoparticles; ELISA, enzyme-linked immunosorbent assay; SEM, standard error of the mean; TNF $\alpha$, tumor necrosis factor $\alpha$; IL, interleukin. 
A
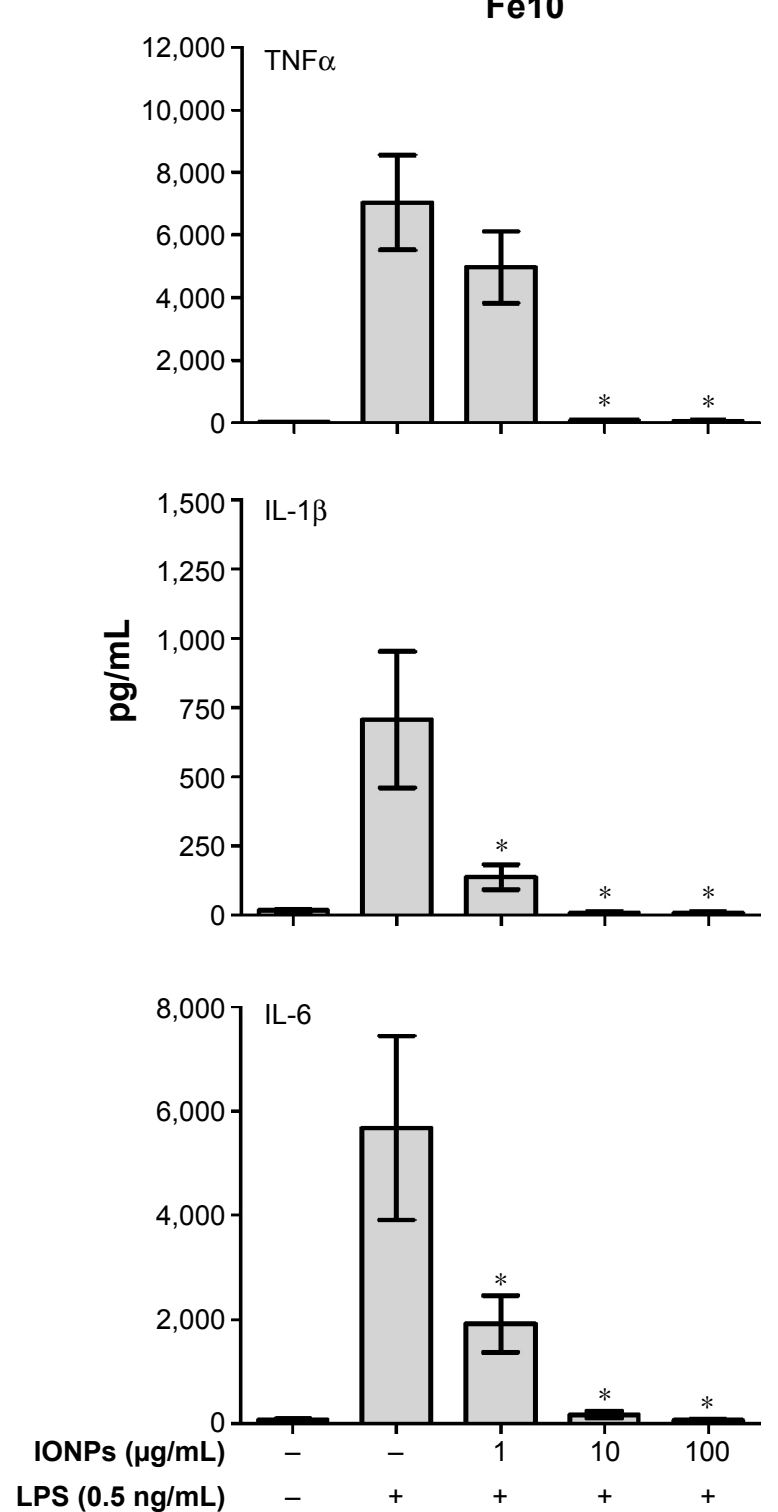

B

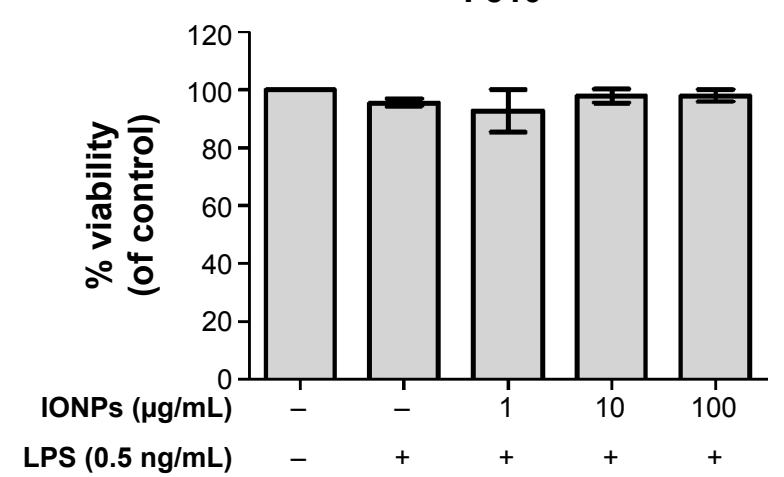

$\mathrm{Fe} 30$
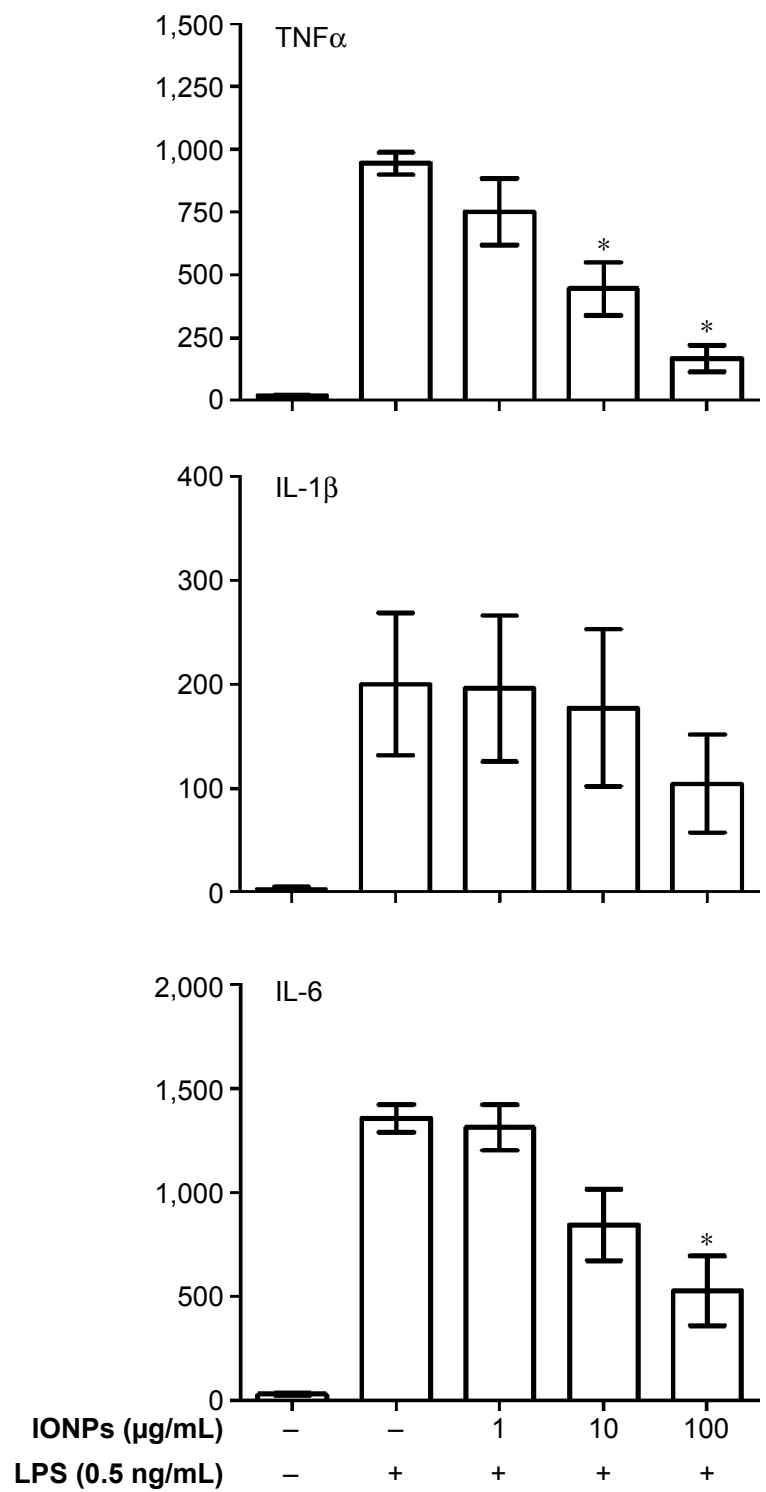

$\mathrm{Fe} 30$

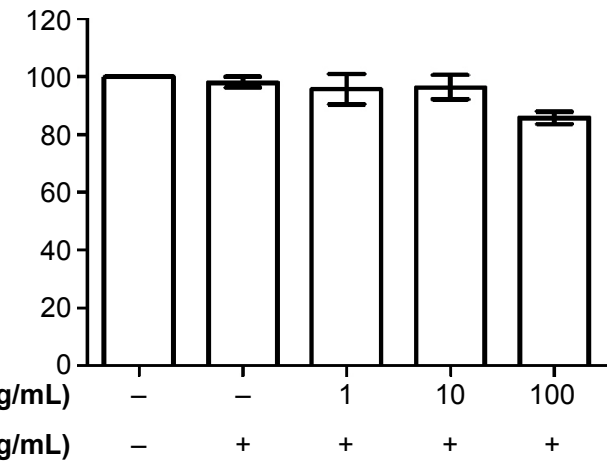

Figure 4 Cytokine response and viability in IONPs-treated primary human monocytes in the presence of TLR4 agonist LPS.

Notes: The cells were co-stimulated with IONPs $(I \mu \mathrm{g} / \mathrm{mL}, 10 \mu \mathrm{g} / \mathrm{mL}$, and $100 \mu \mathrm{g} / \mathrm{mL})$ and LPS $(0.5 \mathrm{ng} / \mathrm{mL})$ for 6 hours. The cytokine concentration released into the medium (A) was measured using ELISA, and the monocyte viability (B) was determined with the alamarBlue assay. Results are expressed as mean \pm SEM; $n=7-9$ for Fe 0 cytokine release, $n=4-6$ for Fe30 cytokine release, and $n=2-3$ for viability. *Statistical significance $(P<0.05)$ compared to LPS alone.

Abbreviations: IONPs, iron oxide nanoparticles; TLR, Toll-like receptor; LPS, lipopolysaccharide; ELISA, enzyme-linked immunosorbent assay; SEM, standard error of the mean; TNF $\alpha$, tumor necrosis factor $\alpha$; IL, interleukin. 
would affect the cytokine response from the monocytes stimulated with IONPs and LPS. As shown in Figure S4, monocytes in cell culture medium containing $10 \%$ and $20 \%$ A+ serum did not show a different cytokine response than cells cultured in medium with $5 \% \mathrm{~A}+$ serum.

To further elucidate the effect of varying the experimental conditions, we subsequently examined the impact of the $10 \mathrm{~nm}$ IONPs together with LPS at different concentrations (Figure 5). The particle-mediated suppression of the LPS-induced TNF $\alpha$ response was dependent on both particle and LPS concentrations, with little effect of $1 \mu \mathrm{g} / \mathrm{mL}$ and $10 \mu \mathrm{g} / \mathrm{mL}$ IONPs for the highest LPS doses $(500-1,000 \mathrm{ng} / \mathrm{mL})$, while a clear inhibition of LPS at high doses was seen with $100 \mu \mathrm{g} / \mathrm{mL}$ IONPs.

\section{mRNA expression of cytokines and $N F \kappa B$ activation}

We hypothesized that the reduced LPS-induced cytokine response upon cell treatment with $10 \mathrm{~nm}$ IONPs might be explained by blocking of TLR4 signaling, transcriptional, or posttranscriptional events. Thus, we examined the LPS-induced cytokine transcription by quantitative realtime polymerase chain reaction. The LPS-induced TNF $\alpha$ mRNA expression was significantly inhibited by high concentrations of IONPs (Figure 6), as were IL-6 and IL-1 $\beta$ expression levels (data not shown). Also, the induction

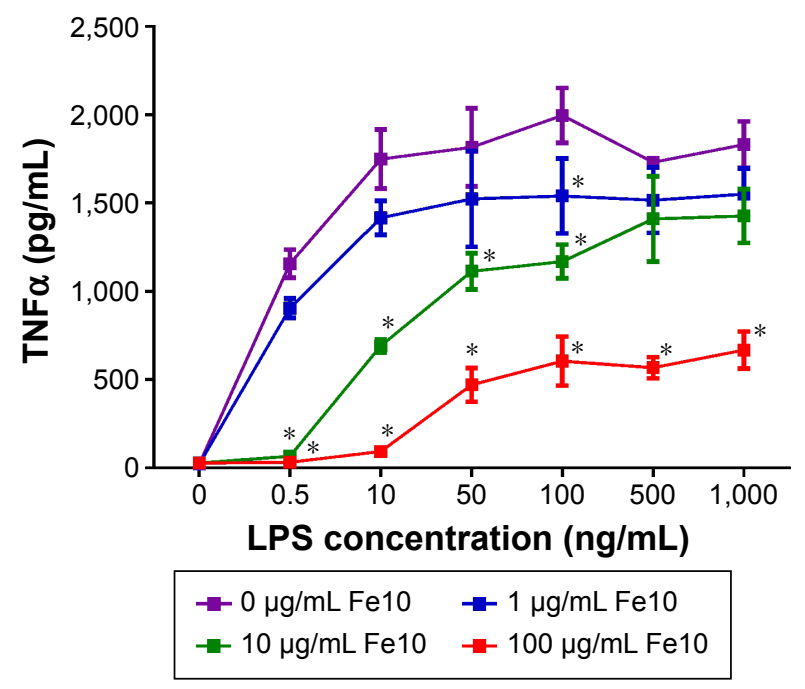

Figure 5 Cytokine response in IONPs-treated primary human monocytes in the presence of LPS.

Notes: The cells were co-stimulated with $10 \mathrm{~nm}$ IONPs $(I \mu \mathrm{g} / \mathrm{mL}, 10 \mu \mathrm{g} / \mathrm{mL}$, and $100 \mu \mathrm{g} / \mathrm{mL})$ and LPS $(0.5 \mathrm{ng} / \mathrm{mL}, 10 \mathrm{ng} / \mathrm{mL}, 50 \mathrm{ng} / \mathrm{mL}, 100 \mathrm{ng} / \mathrm{mL}, 500 \mathrm{ng} / \mathrm{mL}$, and $1,000 \mathrm{ng} / \mathrm{mL}$ ) for 6 hours. TNF $\alpha$ concentration released in the medium was measured using ELISA. Results are expressed as mean \pm SEM $(n=3)$. *Statistical significance $(P<0.05)$ compared to LPS alone.

Abbreviations: IONPs, iron oxide nanoparticles; LPS, lipopolysaccharide; TNF $\alpha$, tumor necrosis factor $\alpha$; ELISA, enzyme-linked immunosorbent assay; SEM, standard error of the mean.

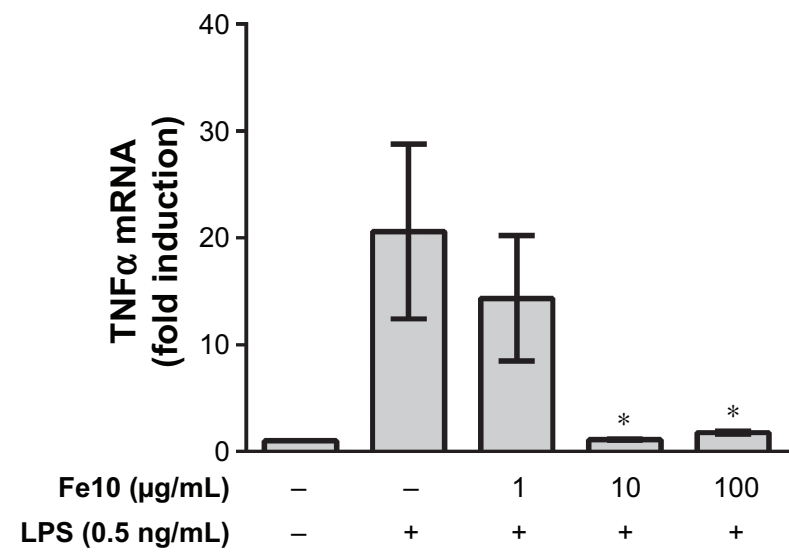

Figure 6 mRNA expression in IONPs-treated primary human monocytes in the presence of LPS.

Notes: The cells were co-stimulated with $10 \mathrm{~nm}$ IONPs $(I \mu \mathrm{g} / \mathrm{mL}, 10 \mu \mathrm{g} / \mathrm{mL}$, and $100 \mu \mathrm{g} / \mathrm{mL})$ and LPS $(0.5 \mathrm{ng} / \mathrm{mL})$ for 2 hours, and TNF $\alpha$ mRNA expression in the lysates of the treated monocytes was determined by $\mathrm{QRT}$-PCR. Results are expressed as mean $\pm \operatorname{SEM}(n=3)$. *Statistical significance $(P<0.05)$ compared to LPS alone. Abbreviations: mRNA, messenger RNA; IONPs, iron oxide nanoparticles; LPS, lipopolysaccharide; TNF $\alpha$, tumor necrosis factor $\alpha$; qRT-PCR, quantitative real-time polymerase chain reaction; SEM, standard error of the mean.

of IFN $\beta$ mRNA expression showed similar patterns (data not shown), suggesting that both TLR4 signaling from the plasma membrane (NFKB pathway) and TLR4 signaling from endosomes (interferon regulatory factor 3 pathway) were antagonized by IONPs and that the mechanisms were upstream of translation.

We further examined the activation of an NFkBdependent luciferase reporter and found that HEK293 cells transiently transfected with TLR4 showed significantly decreased activation of NFKB after co-stimulation with $10 \mathrm{~nm}$ IONPs and $50 \mathrm{ng} / \mathrm{mL}$ LPS (Figure 7). The cytokine

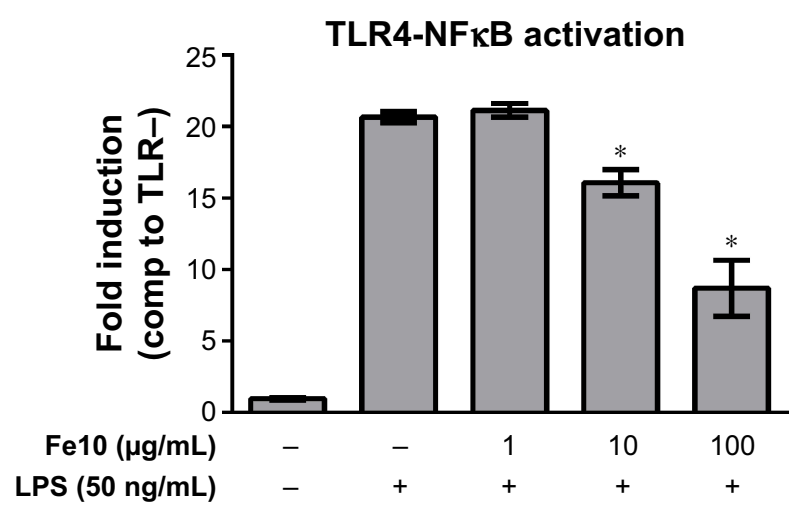

Figure 7 Evaluation of NFKB activation in IONPs-treated HEK293 cells in the presence of LPS.

Notes: HEK293 cells were transiently transfected with TLR4-CDI4-MD2 and costimulated with $10 \mathrm{~nm} 10 N P s(1 \mu \mathrm{g} / \mathrm{mL}, 10 \mu \mathrm{g} / \mathrm{mL}, 100 \mu \mathrm{g} / \mathrm{mL})$ and LPS $(50 \mathrm{ng} / \mathrm{mL})$ for 24 hours. LPS $(50 \mathrm{ng} / \mathrm{mL})$ served as positive control for the activation of TLR4. Results are expressed as mean $\pm \operatorname{SEM}(n=3)$. *Statistical significance $(P<0.05)$ compared to LPS alone.

Abbreviations: NFKB, nuclear factor kappa B; IONPs, iron oxide nanoparticles; LPS, lipopolysaccharide; TLR, Toll-like receptor; SEM, standard error of the mean; comp, compared. 
release from the HEK293 cells was similar to the release pattern from the monocytes at the same LPS concentration (Figure 5), which suggests that the effect of IONPs on LPS activation of TLR4 is not cell type restricted.

\section{Fluorescence confocal microscopy}

Having demonstrated that co-stimulation of monocytes with $10 \mathrm{~nm}$ IONPs and LPS resulted in decreased LPSinduced NFKB activation and release of proinflammatory cytokines, we hypothesized that IONPs impair the LPS binding to CD14/TLR4 and subsequent uptake of LPS in monocytes, which is reported to be dependent on CD14. ${ }^{22}$ Examination of cellular uptake was done using confocal microscopy and Alexa594-labeled LPS (Figure 8). Internalization of Alexa594-labeled LPS by monocytes resulted in a focal staining pattern. Co-stimulation of the cells with IONPs and LPS decreased the cell-associated Alexa594labeled LPS fluorescence in a dose-dependent manner, with minimal staining at $100 \mu \mathrm{g} / \mathrm{mL}$ IONPs (Figure 8). Cytokine analyses with Alexa594-labeled LPS in the absence and presence of IONPs were comparable to the results with nonlabeled LPS (data not shown), indicating that the fluorescent dye does not interfere with the biological activity of the Alexa594-labeled LPS. Thus, there is a correlation of IONPs inhibiting the LPS-induced cytokine production and LPS uptake.

\section{LPS adsorption onto the nanoparticle surface}

To test if the inhibition of the LPS-induced cytokine production and the reduced uptake of Alexa594-labeled LPS in the presence of IONPs in monocytes could be due to LPS adsorption onto the particle surface, we performed centrifugation experiments and treated monocytes with the supernatants and resuspended pellets. UV-vis absorbance measurements showed that the IONPs were pelleted by centrifugation (Figure 9A). Centrifugation of medium containing $0.5 \mathrm{ng} / \mathrm{mL}$ or $100 \mathrm{ng} / \mathrm{mL}$ LPS did not impact the level
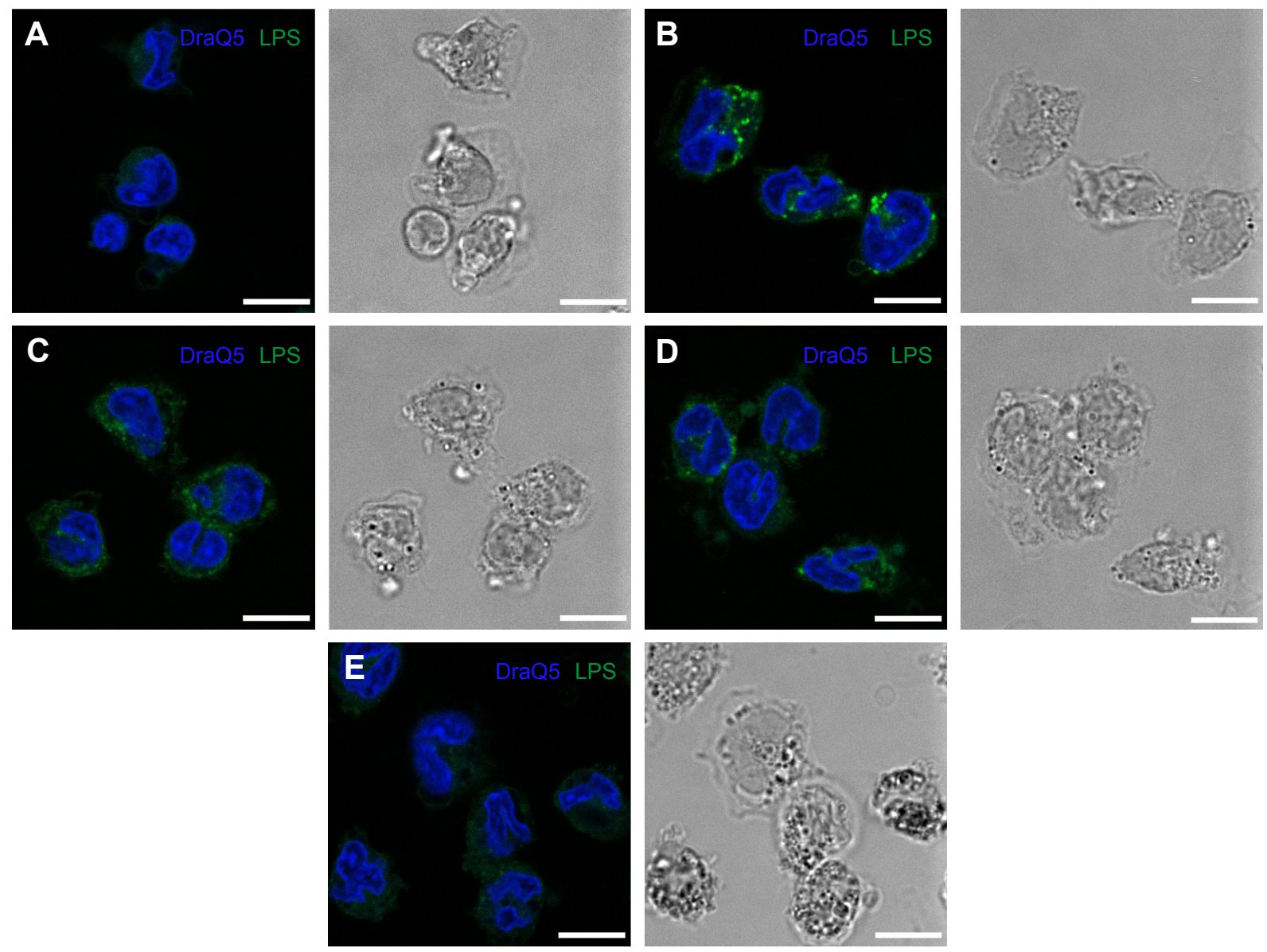

Figure 8 Confocal microscopic analysis of LPS-stimulated primary human monocytes in the presence of IONPs.

Notes: Cellular uptake of Alexa594-labeled LPS (100 ng/mL) in the absence and presence of $10 \mathrm{~nm} 10 \mathrm{ONP}(1 \mu \mathrm{g} / \mathrm{mL}$, $10 \mu \mathrm{g} / \mathrm{mL}$, and I00 $\mu \mathrm{g} / \mathrm{mL})$ was evaluated after $2 \mathrm{hours}$. Left side: Fluorescence mode. Right side: Transmission light mode. (A) Medium. (B) LPS. (C) I $\mu \mathrm{g} / \mathrm{mL}$ Fel0 and LPS. (D) I0 $\mu \mathrm{g} / \mathrm{mL}$ Fel0 and LPS. (E) I00 $\mu \mathrm{g} / \mathrm{mL}$ Fe I0 and LPS. Scale bar is $10 \mu \mathrm{m}$.

Abbreviations: LPS, lipopolysaccharide; IONPs, iron oxide nanoparticles. 
A

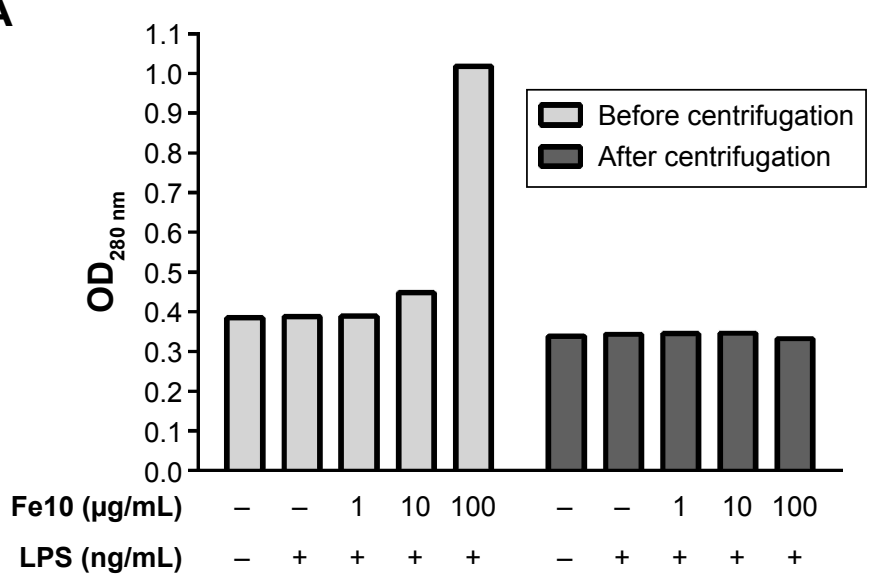

B

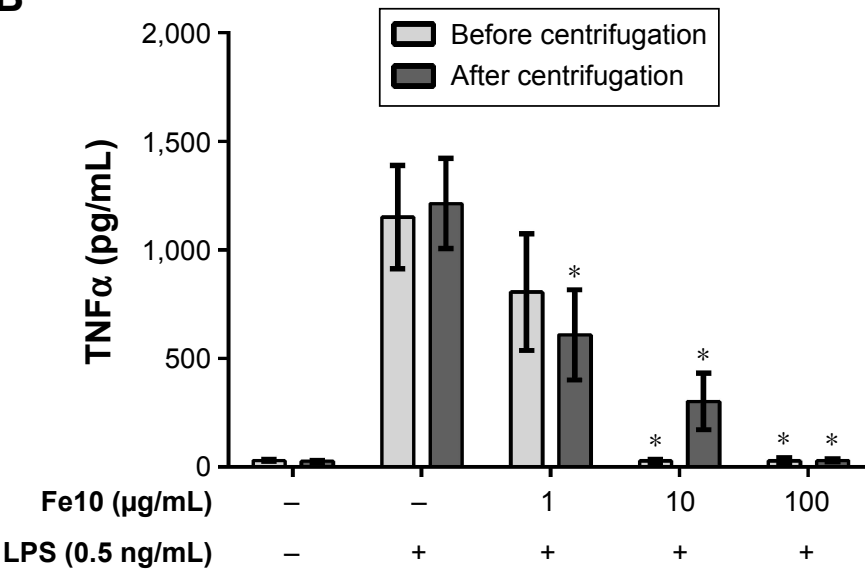

C

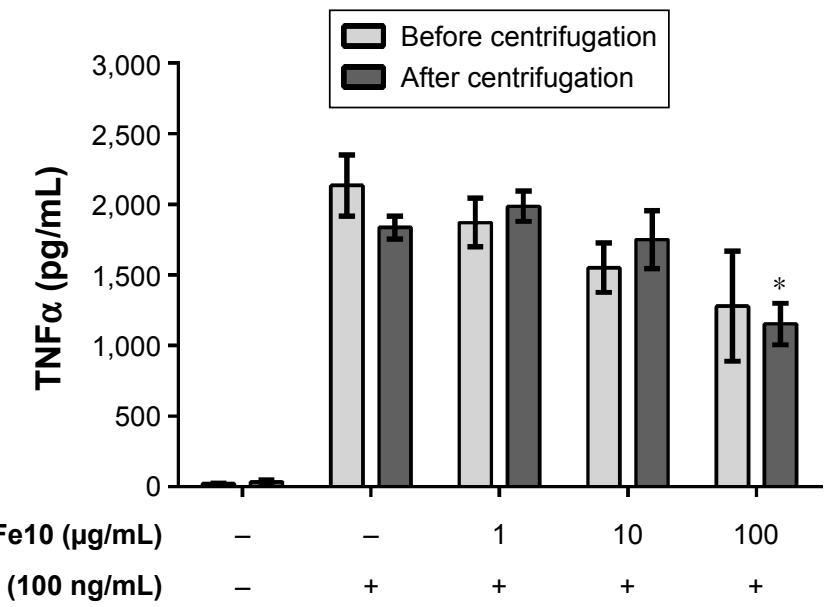

D

Resuspended pellets

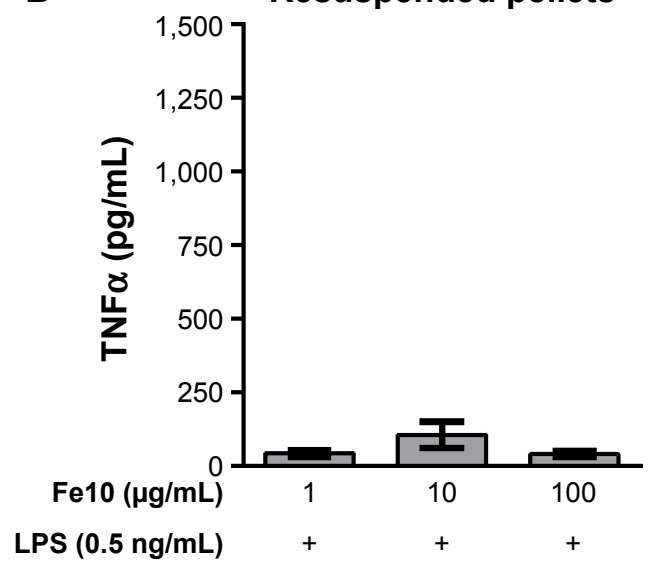

E

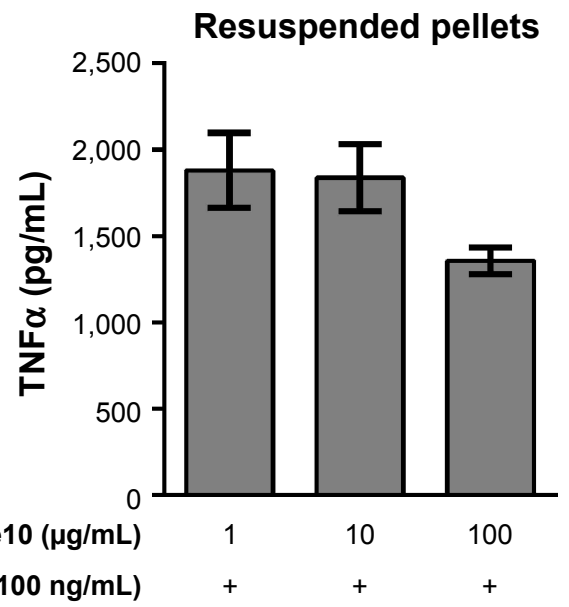

Figure 9 LPS adsorption to the $10 \mathrm{~nm}$ IONPs and its effects on the activity of the IONPs in TLR signaling.

Notes: Cell-free samples containing both $10 \mathrm{~nm} 1 \mathrm{ONPs}(1 \mu \mathrm{g} / \mathrm{mL}, 10 \mu \mathrm{g} / \mathrm{mL}$, and $100 \mu \mathrm{g} / \mathrm{mL})$ and LPS $(0.5 \mathrm{ng} / \mathrm{mL}$ and $100 \mathrm{ng} / \mathrm{mL})$ were centrifuged at $15,000 \times \mathrm{g}$ for 2 hours $\left(\right.$ at $4^{\circ} \mathrm{C}$ ) to pellet the nanoparticles. (A) Removal of the $10 \mathrm{~nm}$ IONPs after centrifugation was measured using absorbance at $280 \mathrm{~nm}$. Primary human monocytes were treated with the supernatants before and after centrifugation and resuspended pellets after centrifugation. (B, D) I0 nm IONPs and LPS at $0.5 \mathrm{ng} / \mathrm{mL}$. (C, E) I0 nm IONPs and LPS at $100 \mathrm{ng} / \mathrm{mL}$. Results are expressed as mean $\pm \operatorname{SEM}(n=3)$. *Statistical significance $(P<0.05)$ compared to LPS alone in the respective group (before and after centrifugation). No statistical significant difference between the two groups was found.

Abbreviations: LPS, lipopolysaccharide; IONPs, iron oxide nanoparticles; TLR, Toll-like receptor; SEM, standard error of the mean; TNF $\alpha$, tumor necrosis factor $\alpha$.

of TNF $\alpha$ production in subsequent monocyte stimulation experiments (Figure 9B and C).

With $10 \mu \mathrm{g} / \mathrm{mL}$ and $100 \mu \mathrm{g} / \mathrm{mL}$ IONPs and $0.5 \mathrm{ng} / \mathrm{mL}$ LPS, the LPS-induced TNF $\alpha$ production was similarly inhibited before and after centrifugation, showing that the removal of the IONPs did not restore the original LPS bioactivity. The inhibited LPS activity in the supernatants after centrifugation is likely due to LPS adsorption onto the 

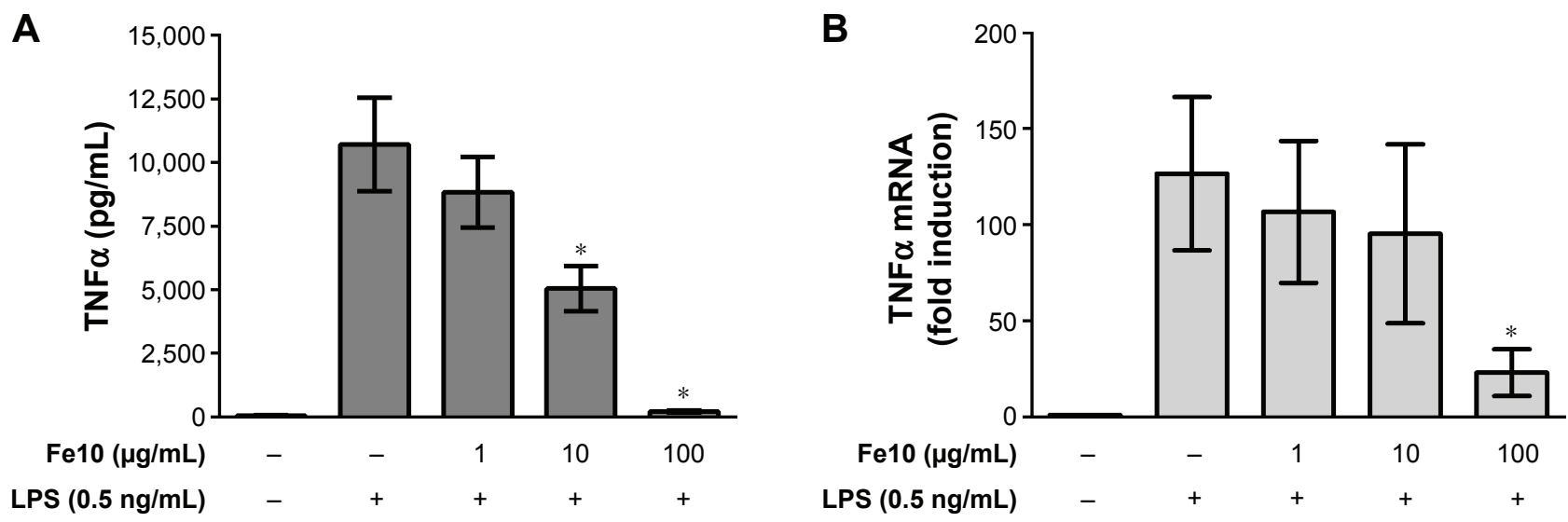

Figure 10 Cytokine response in LPS-stimulated primary human monocytes pretreated with IONPs.

Notes: The cells were pretreated with $10 \mathrm{~nm} 10 \mathrm{NPs}(1 \mu \mathrm{g} / \mathrm{mL}, 10 \mu \mathrm{g} / \mathrm{mL}$, and $100 \mu \mathrm{g} / \mathrm{mL})$ for 3 hours. After three times washing with Hank's solution, LPS (0.5 ng/mL) was added for 6 hours. (A) TNF $\alpha$ concentration released in the medium was measured using ELISA $(n=5)$. (B) TNF $\alpha$ mRNA expression in the lysates of the treated monocytes was determined by qRT-PCR $(n=3)$. Results are expressed as mean \pm SEM. *Statistical significance $(P<0.05)$ compared to LPS alone.

Abbreviations: LPS, lipopolysaccharide; IONPs, iron oxide nanoparticles; TNF $\alpha$, tumor necrosis factor $\alpha$; ELISA, enzyme-linked immunosorbent assay; mRNA, messenger RNA; qRT-PCR, quantitative real-time polymerase chain reaction; SEM, standard error of the mean.

particle surface. Moreover, stimulation of monocytes with the resuspended pellets did not result in cytokine production (Figure 9D), which suggests that IONPs blunt the biological activity of LPS, possibly by sterical hindrance of adsorbed LPS or by adsorption of CD14 or other accessory proteins necessary for LPS binding to TLR4 and thus TLR4 signaling.

The stimulation of monocytes with IONPs and $100 \mathrm{ng} / \mathrm{mL}$ LPS resulted in a particle dose-dependent decrease in LPSinduced TNF $\alpha$ production before and after centrifugation of the exposure solutions (Figure 9C). However, in this case, the stimulation of the cells with the resuspended pellets resulted in a marked TNF $\alpha$ production, similar to the particle-free supernatants (Figure 9E). This suggests that with a greater amount of LPS in the nanoparticle solution, LPS still retains some of its biological activity, which could be due to a higher amount of adsorbed LPS to the IONPs or released LPS, which is biologically active. Using high concentrations of Alexa594-labeled LPS (100 ng/mL and $500 \mathrm{ng} / \mathrm{mL}$ ), we could show the LPS adsorption to the IONPs directly (Figure S5).

Altogether, the IONPs reduced the TLR4-activating activity of LPS and the CD14/TLR4-dependent cellular LPS internalization most likely by LPS adsorption onto the nanoparticle surface.

\section{Pretreatment of monocytes with IONPs and subsequent stimulation with LPS}

In addition to co-stimulation experiments, monocytes were pretreated with IONPs, washed, and subsequently stimulated with LPS. Pretreatment with $100 \mu \mathrm{g} / \mathrm{mL}$ IONPs also reduced the LPS-induced TNF $\alpha$ production, while co-treatment showed somewhat more potent effects of IONPs (Figure 10).

\section{Discussion}

We investigated whether IONPs affect the production of proinflammatory cytokines in primary human monocytes in the presence and absence of TLR4 agonist LPS. The aim was to examine the capacity of IONPs to alter the reactivity of monocytes to LPS. Co-stimulation of the immune system to more than one agent concomitantly is very common in real life, and considering the use of engineered nanoparticles and nanomaterials in medical applications, the study of co-stimulation is highly relevant in the field of nano-immunotoxicology. It has been previously suggested that nanomaterials should be evaluated in the presence of agonists such as the bacterial component LPS. ${ }^{23}$

Primary human monocytes were examined because of the following reasons: first, IONPs are used in medical applications and thus are likely to be administered intravenously. Blood monocytes are the first cells to come in contact with the injected nanoparticles, and it is therefore expected that these cells are directly involved in the uptake of and interaction with nanoparticles. Second, monocytes are very sensitive to trace amounts of LPS, ${ }^{24}$ which makes them a suitable cell model for testing co-stimulation of nanoparticles and LPS. Furthermore, primary cells possess higher sensitivity compared to immortalized cell lines and represent the response of normal cells. Thus, they might closely reflect the de facto responses generated in vivo. ${ }^{25}$

Prior to the cell studies, it is crucial to identify biological contaminants in the nanoparticle suspensions in order to 
correctly interpret the immunotoxicological data. ${ }^{9}$ This is especially important when working with human monocytes, as these cells express high levels of TLR4 and are thus very sensitive to endotoxin, ${ }^{24}$ as mentioned earlier. LPS (or endotoxin) is most often assessed using the LAL assay. However, nanoparticles frequently interfere with this type of assay, ${ }^{26}$ which was also the case in our study. Therefore, we chose a more sensitive, cell-based reporter assay, which in addition to LPS contamination (TLR4 agonist) also assessed possible contamination with TLR2 agonists. The exclusion of nanoparticle contamination with TLR2 or TLR4 agonists was especially important in our study, as we investigated possible synergistic effects of co-stimulation with the nanoparticles and a TLR agonist.

Nanoparticle uptake by professional phagocytes can result in the production of proinflammatory cytokines. ${ }^{9}$ Here, we demonstrated that $10 \mathrm{~nm}$ and $30 \mathrm{~nm}$ IONPs were taken up by primary human monocytes, which is in agreement with previous work on IONPs that showed uptake via scavenger receptors. ${ }^{27}$ Internalization via scavenger receptors does not result in proinflammatory responses. Although we did not determine the uptake mechanism in our study, the IONPs alone did not induce the release of TNF $\alpha$, IL- 6 , and IL-1 $\beta$ from primary human monocytes, which is in line with previous findings ${ }^{28}$ and favors internalization via scavenger receptors.

Intriguingly, we found that the $10 \mathrm{~nm}$ and $30 \mathrm{~nm}$ IONPs inhibited LPS-induced cytokine production in monocytes in a particle and LPS dose-dependent manner, which was not due to a loss in viability. These findings are in agreement with other studies using human monocytes/macrophages, LPS and pollution particles, ${ }^{29,30}$ or silver oxide nanoparticles. ${ }^{24}$ However, our findings are in contrast to some other studies, where nanoparticles did not affect cytokine secretion mediated by TLR agonists ${ }^{31,32}$ or enhanced the cytokine secretion. ${ }^{33,34}$ The contrasting results could be explained by the use of different nanoparticles (ie, different types with different shapes and surface coatings/charge) and cellular models. ${ }^{35}$ Studies with mouse cell lines might not accurately predict responses in humans, as there are differences in TLR expression, regulation, and function between mice and humans. ${ }^{36}$ Also, differences in LPS type, concentration, and potency could explain the contrasting findings. Unfortunately, these studies did not state the source of LPS used.

In our search for the mechanism(s) underlying this response, we focused first on excluding experimental artifacts, before conducting more mechanistical studies. As experimental conditions such as cellular adherence and serum concentration in the cell culture medium could affect the results of in vitro studies, ${ }^{8}$ we investigated if these factors would influence the cytokine production in monocytes in our study. The results showed no differences in the cytokine response upon cellular co-stimulation with IONPs and LPS under different conditions (ie, nonadherent cells and higher serum concentrations). Furthermore, one has to be aware of possible interferences of nanoparticles with ELISA and other immunoassays before interpreting cytokine inhibition studies. In order to correctly interpret the ELISA readouts for the cytokine production, we determined possible adsorption of the cytokines to the nanoparticles. Previous studies have demonstrated that nanoparticles can adsorb cytokines released from the cells in the medium, which may interfere with the accurate assessment of the inflammatory responses elicited by these particles. ${ }^{20,37-40}$ However, cytokine adsorption to the nanoparticles as possible artifact could be eliminated as cause for the low cytokine concentrations measured in our study. The IONPs did not absorb TNF $\alpha$ and IL-1 $\beta$. Only the $10 \mathrm{~nm}$ particles at the highest concentration adsorbed IL-6, which is in agreement with a study by Veranth et al, ${ }^{41}$ showing that IONPs $>100 \mu \mathrm{g} / \mathrm{mL}$ reduced the measured IL-6 concentration.

Having excluded technical and experimental artifacts, we conducted further mechanistical studies and showed that the reduced cytokine production correlated with a reduced activation of the transcription factor NFKB and reduced cytokine gene expression, which correlated with impaired LPS uptake in the monocytes in the presence of IONPs. As internalization of LPS by monocytes is dependent on CD14, ${ }^{22}$ this suggests that IONPs interfere with LBP/CD14 binding of LPS and subsequent activation of TLR4/MD2, possibly by LPS adsorption onto the nanoparticles' surface. At high LPS concentrations ( $100 \mathrm{ng} / \mathrm{mL})$, the resuspended pellets containing the nanoparticles induced a marked cytokine response, indicating that LPS is associated with the nanoparticles and can still retain some of its inflammatory activity. In contrast, at low LPS concentrations $(0.5 \mathrm{ng} / \mathrm{mL})$, no cytokine release from the monocytes was detected when the cells were stimulated with the resuspended pellets. This suggests that the proinflammatory activity of LPS was likely to be inactivated, possibly due to steric hindrance of the LPS molecules on the nanoparticle surface. Altogether, the data suggest a mechanism whereby LPS adsorption to the IONPs results in a partial or complete loss of biological activity, dependent on both the LPS and the IONP concentrations.

Although we found that the IONPs could adsorb LPS, this interaction is likely not the only inhibitory 
mechanism for the following two reasons: first, the $10 \mathrm{~nm}$ IONPs suppressed the LPS-induced cytokine response at high LPS concentrations $(1,000 \mathrm{ng} / \mathrm{mL})$ at which the LPS adsorption/binding is saturated (Figures 5 and 8). This suggests that the inhibitory activity of high concentrations of IONPs is not solely due to LPS adsorption onto the nanoparticle surface. Second, pretreatment of the monocytes with $10 \mathrm{~nm}$ IONPs and subsequent stimulation with LPS led to a dose-dependent reduction in cytokine production different from the response in the co-stimulation experiments, which suggests that other cellular mechanisms induced by the IONPs might play a role in the observed effects. Once taken up by the monocytes, it is likely that the IONPs modulate intracellular signaling pathways that lead to a reduction of NFKB activation and cytokine mRNA expression and protein production. In fact, it has been shown that pretreatment of bone marrow-derived macrophages with superparamagnetic IONPs caused reprogramming of nearly 500 genes regulated in response to LPS challenge. ${ }^{42}$ Another study suggested that the activation of scavenger receptors could be associated with the inhibition of inflammatory mediators such as LPS. ${ }^{43}$ In any case, IONP uptake by monocytes might determine not only the monocyte response to later LPS challenge but also their differentiation into macrophages or dendritic cells after entering tissues. It has been suggested that iron regulates the functional plasticity in macrophages. In fact, a previous study indicates that superparamagnetic IONPs induce a shift from M2 macrophages to M1 subtype. ${ }^{44}$ How the possible polarizing effect of IONPs on monocyte/macrophage differentiation influences further regulation of inflammatory reactions needs to be investigated.

Further research is also needed to clarify the additional mechanisms of how IONPs can suppress the LPS-induced cytokine response in human monocytes and whether this response is unique to IONPs. Preliminary data from our group with dopamine- and dextran-coated IONPs showed a similar LPS-induced inhibition of the TNF $\alpha$ response at a high NP concentration $(100 \mu \mathrm{g} / \mathrm{mL})$. However, costimulation experiments with uncoated $\mathrm{TiO}_{2}, \mathrm{ZnO}, \mathrm{CeO}$, and $\mathrm{SiO}_{2}$ nanoparticles resulted in an increase in LPS-induced TNF $\alpha$ response. These results may indicate that the coating/ surface charge is relevant in the mechanism by which the nanoparticles adsorb LPS and inhibit the production of proinflammatory cytokines. Nevertheless, more research is needed to determine the role of the core material and surface coating/charge in the inhibition of proinflammatory cytokine production.

\section{Conclusion}

Overall, this study showed that $10 \mathrm{~nm}$ and $30 \mathrm{~nm}$ IONPs have no inflammatory effect per se on primary human monocytes but can modulate the LPS-induced cytokine responses in these cells. The inhibition of the LPS-induced proinflammatory cytokine production was found to be both LPS and particle dose-dependent. The observed effects are partly caused by LPS adsorption onto the particle surface, which reduced the bioavailability of LPS for cellular receptors such as CD14 and TLR4 and which subsequently reduced the LPS internalization by monocytes. Additionally, results from particle pretreatment experiments indicate that other cellular mechanisms also play a role in the observed effects.

\section{Acknowledgments}

The authors thank the Blood Bank at St Olav's Hospital in Trondheim, Norway, for supplying the buffy coats and Doctor Syed Ali (US FDA) for providing the iron oxide nanoparticles. Furthermore, we thank Nan E Tostrup Skogaker and Bjørnar Sporsheim for their technical support with TEM and the fluorescence confocal microscopy, respectively, which was conducted at the Cellular and Molecular Imaging Core Facility, Norwegian University of Science and Technology (NTNU). JS and AMN are co-senior authors. SG was financed by NANOLAB, Norwegian University of Science and Technology (NTNU), where most of the particle characterisation was done.

\section{Disclosure}

The authors report no conflicts of interest in this work.

\section{References}

1. Choi JW, Nam Sun W. Nanoparticles in biomedical applications and their safety concerns. In: Fazel R, editor. Biomedical Engineering - From Theory to Applications. Croatia: InTech; 2011:299-314.

2. Kawai T, Akira S. TLR signaling. Cell Death Differ. 2006;13(5): 816-825.

3. Zolnik BS, Gonzalez-Fernandez A, Sadrieh N, Dobrovolskaia MA. Nanoparticles and the immune system. Endocrinology. 2010;151(2): 458-465

4. Huber DL. Synthesis, properties, and applications of iron nanoparticles. Small. 2005;1(5):482-501.

5. Khan MI, Mohammad A, Patil G, Naqvi SA, Chauhan LK, Ahmad I. Induction of ROS, mitochondrial damage and autophagy in lung epithelial cancer cells by iron oxide nanoparticles. Biomaterials. 2012;33(5):1477-1488.

6. Pisanic TR 2nd, Blackwell JD, Shubayev VI, Finones RR, Jin S. Nanotoxicity of iron oxide nanoparticle internalization in growing neurons. Biomaterials. 2007;28(16):2572-2581.

7. Liu SY, Long L, Yuan Z, Yin LP, Liu R. Effect and intracellular uptake of pure magnetic $\mathrm{Fe} 3 \mathrm{O} 4$ nanoparticles in the cells and organs of lung and liver. Chin Med J. 2009;122(15):1821-1825.

8. Soenen SJ, De Cuyper M. Assessing iron oxide nanoparticle toxicity in vitro: current status and future prospects. Nanomedicine (Lond). 2010;5(8): $1261-1275$. 
9. Dobrovolskaia MA, McNeil SE. Immunological properties of engineered nanomaterials. Nat Nanotechnol. 2007;2(8):469-478.

10. Yang EJ, Choi IH. Immunostimulatory effects of silica nanoparticles in human monocytes. Immune Netw. 2013;13(3):94-101.

11. Sahu D, Kannan GM, Vijayaraghavan R. Size-dependent effect of zinc oxide on toxicity and inflammatory potential of human monocytes. J Toxicol Environ Health A. 2014;77(4):177-191.

12. Lankoff A, Arabski M, Wegierek-Ciuk A, et al. Effect of surface modification of silica nanoparticles on toxicity and cellular uptake by human peripheral blood lymphocytes in vitro. Nanotoxicology. 2013;7(3): 235-250.

13. Inoue K, Takano H. Aggravating impact of nanoparticles on immunemediated pulmonary inflammation. ScientificWorldJournal. 2011; 11:382-390.

14. Inoue $\mathrm{K}$, Takano $\mathrm{H}$, Yanagisawa R, et al. Effects of inhaled nanoparticles on acute lung injury induced by lipopolysaccharide in mice. Toxicology. 2007;238(2-3):99-110.

15. Nygaard UC, Hansen JS, Samuelsen M, Alberg T, Marioara CD, Lovik M. Single-walled and multi-walled carbon nanotubes promote allergic immune responses in mice. Toxicol Sci. 2009;109(1): $113-123$.

16. Laverny G, Casset A, Purohit A, et al. Immunomodulatory properties of multi-walled carbon nanotubes in peripheral blood mononuclear cells from healthy subjects and allergic patients. Toxicol Lett. 2013; 217(2):91-101.

17. Ma JS, Kim WJ, Kim JJ, et al. Gold nanoparticles attenuate LPS-induced NO production through the inhibition of NF-kappaB and IFN-beta/ STAT1 pathways in RAW264.7 cells. Nitric Oxide. 2010;23(3): 214-219.

18. Bajaj G, Van Alstine WG, Yeo Y. Zwitterionic chitosan derivative, a new biocompatible pharmaceutical excipient, prevents endotoxin-mediated cytokine release. PLoS One. 2012;7(1):e30899.

19. Tu J, Xu Y, Xu J, Ling Y, Cai Y. Chitosan nanoparticles reduce LPSinduced inflammatory reaction via inhibition of NF-kappaB pathway in Caco-2 cells. Int J Biol Macromol. 2016;86:848-856.

20. Kocbach A, Totlandsdal AI, Låg M, Refsnes M, Schwarze PE. Differential binding of cytokines to environmentally relevant particles: a possible source for misinterpretation of in vitro results? Toxicol Lett. 2008;176(2):131-137.

21. Herseth JI, Totlandsdal AI, Bytingsvik S, Kaur J, Noer M, Bolling AK. The challenge of obtaining correct data for cellular release of inflammatory mediators after in vitro exposure to particulate matter. Toxicol Lett. 2013;221(2):110-117.

22. Dunzendorfer S, Lee HK, Soldau K, Tobias PS. TLR4 is the signaling but not the lipopolysaccharide uptake receptor. J Immunol. 2004; 173(2):1166-1170.

23. Suri SS, Fenniri H, Singh B. Nanotechnology-based drug delivery systems. J Occup Med Toxicol. 2007;2:16

24. Oostingh GJ, Casals E, Italiani P, et al. Problems and challenges in the development and validation of human cell-based assays to determine nanoparticle-induced immunomodulatory effects. Part Fibre Toxicol. 2011;8(1):8

25. Pfaller T, Puntes V, Casals E, Duschl A, Oostingh GJ. In vitro investigation of immunomodulatory effects caused by engineered inorganic nanoparticles - the impact of experimental design and cell choice. Nanotoxicology. 2009;3(1):46-59.

26. Smulders S, Kaiser JP, Zuin S, et al. Contamination of nanoparticles by endotoxin: evaluation of different test methods. Part Fibre Toxicol. 2012;9:41

27. von Zur Muhlen C, von Elverfeldt D, Bassler N, et al. Superparamagnetic iron oxide binding and uptake as imaged by magnetic resonance is mediated by the integrin receptor Mac-1 (CD11b/CD18): implications on imaging of atherosclerotic plaques. Atherosclerosis. 2007; 193(1):102-111.
28. Gojova A, Guo B, Kota RS, Rutledge JC, Kennedy IM, Barakat AI. Induction of inflammation in vascular endothelial cells by metal oxide nanoparticles: effect of particle composition. Environ Health Perspect. 2007;115(3):403-409.

29. Becker S, Mundandhara S, Devlin RB, Madden M. Regulation of cytokine production in human alveolar macrophages and airway epithelial cells in response to ambient air pollution particles: further mechanistic studies. Toxicol Appl Pharmacol. 2005;207(2 suppl):269-275.

30. Amakawa K, Terashima T, Matsuzaki T, Matsumaru A, Sagai M, Yamaguchi K. Suppressive effects of diesel exhaust particles on cytokine release from human and murine alveolar macrophages. Exp Lung Res. 2003;29(3):149-164.

31. Castillo PM, Herrera JL, Fernandez-Montesinos R, et al. Tiopronin monolayer-protected silver nanoparticles modulate IL-6 secretion mediated by Toll-like receptor ligands. Nanomedicine (Lond). 2008; 3(5):627-635.

32. Cejudo-Guillen M, Ramiro-Gutierrez ML, Labrador-Garrido A, Diaz-Cuenca A, Pozo D. Nanoporous silica microparticle interaction with Toll-like receptor agonists in macrophages. Acta Biomater. 2012;8(12):4295-4303.

33. Liu Z, Li W, Wang F, et al. Enhancement of lipopolysaccharide-induced nitric oxide and interleukin- 6 production by PEGylated gold nanoparticles in RAW264.7 cells. Nanoscale. 2012;4(22):7135-7142.

34. Chapekar MS, Zaremba TG, Kuester RK, Hitchins VM. Synergistic induction of tumor necrosis factor alpha by bacterial lipopolysaccharide and lipoteichoic acid in combination with polytetrafluoroethylene particles in a murine macrophage cell line RAW 264.7. J Biomed Mater Res. 1996;31(2):251-256.

35. Li Y, Boraschi D. Endotoxin contamination: a key element in the interpretation of nanosafety studies. Nanomedicine (Lond). 2016;11(3): 269-287.

36. Rehli M. Of mice and men: species variations of Toll-like receptor expression. Trends Immunol. 2002;23(8):375-378.

37. Val S, Hussain S, Boland S, Hamel R, Baeza-Squiban A, Marano F. Carbon black and titanium dioxide nanoparticles induce pro-inflammatory responses in bronchial epithelial cells: need for multiparametric evaluation due to adsorption artifacts. Inhal Toxicol. 2009;21(suppl 1): $115-122$.

38. Hussain S, Al-Nsour F, Rice AB, et al. Cerium dioxide nanoparticles do not modulate the lipopolysaccharide-induced inflammatory response in human monocytes. Int J Nanomedicine. 2012;7:1387-1397.

39. Hussain S, Boland S, Baeza-Squiban A, et al. Oxidative stress and proinflammatory effects of carbon black and titanium dioxide nanoparticles: role of particle surface area and internalized amount. Toxicology. 2009;260(1-3):142-149.

40. Ilinskaya AN, Dobrovolskaia MA. Immunosuppressive and antiinflammatory properties of engineered nanomaterials. BrJ Pharmacol. 2014;171(17):3988-4000.

41. Veranth JM, Kaser EG, Veranth MM, Koch M, Yost GS. Cytokine responses of human lung cells (BEAS-2B) treated with micron-sized and nanoparticles of metal oxides compared to soil dusts. Part Fibre Toxicol. 2007;4:2.

42. Kodali V, Littke MH, Tilton SC, et al. Dysregulation of macrophage activation profiles by engineered nanoparticles. ACS Nano. 2013;7(8): 6997-7010.

43. Dutta D, Sundaram SK, Teeguarden JG, et al. Adsorbed proteins influence the biological activity and molecular targeting of nanomaterials. Toxicol Sci. 2007;100(1):303-315.

44. Laskar A, Eilertsen J, Li W, Yuan XM. SPION primes THP1 derived M2 macrophages towards M1-like macrophages. Biochem Biophys Res Commun. 2013;441(4):737-742. 


\section{Supplementary materials}

A

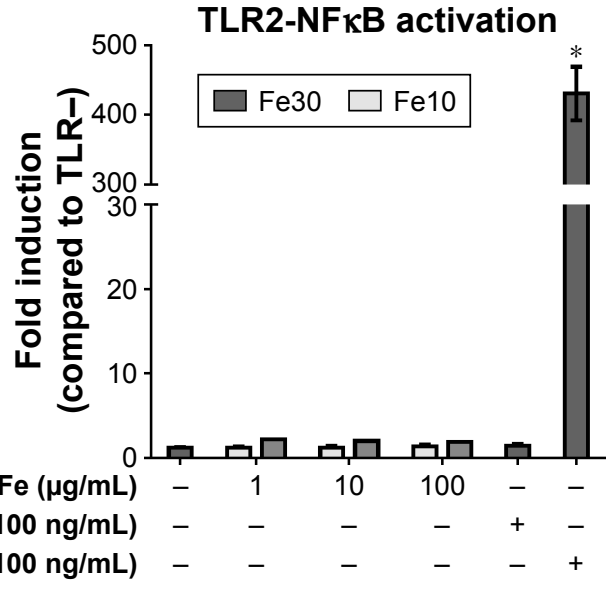

B

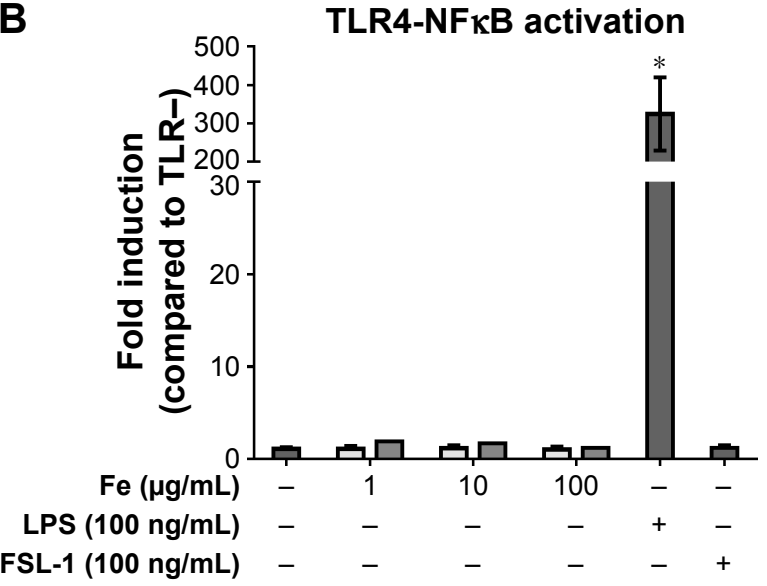

Figure SI Evaluation of biological contamination of the IONPs.

Notes: A luciferase reporter cell assay was used to assess contamination of the IONPs with (A) TLR2 and (B) TLR4 agonists. Human embryonic kidney (HEK293) cells were transiently transfected with a luciferase NFKB reporter plasmid (ELAM-luc) together with either vector only (TLR-), TLR2+/CDI4, or TLR4+/MD2+/CDI4 plasmids. The cells were treated with $10 \mathrm{~nm}$ and $30 \mathrm{~nm}$ IONPs $(1 \mu \mathrm{g} / \mathrm{mL}, 10 \mu \mathrm{g} / \mathrm{mL}, 100 \mu \mathrm{g} / \mathrm{mL}$ ) for 24 hours. TLR4 agonist LPS (I00 ng/mL) and TLR2 agonist FSL-I (I00 ng/mL) served as positive controls for the activation of TLR4 and TLR2, respectively. Results are expressed as mean \pm SEM ( $n=3)$.

Abbreviations: IONPs, iron oxide nanoparticles; TLR, Toll-like receptor; NFKB, nuclear factor kappa B; LPS, lipopolysaccharide; FSL-I, fibroblast-stimulating lipopeptide I; SEM, standard error of the mean.
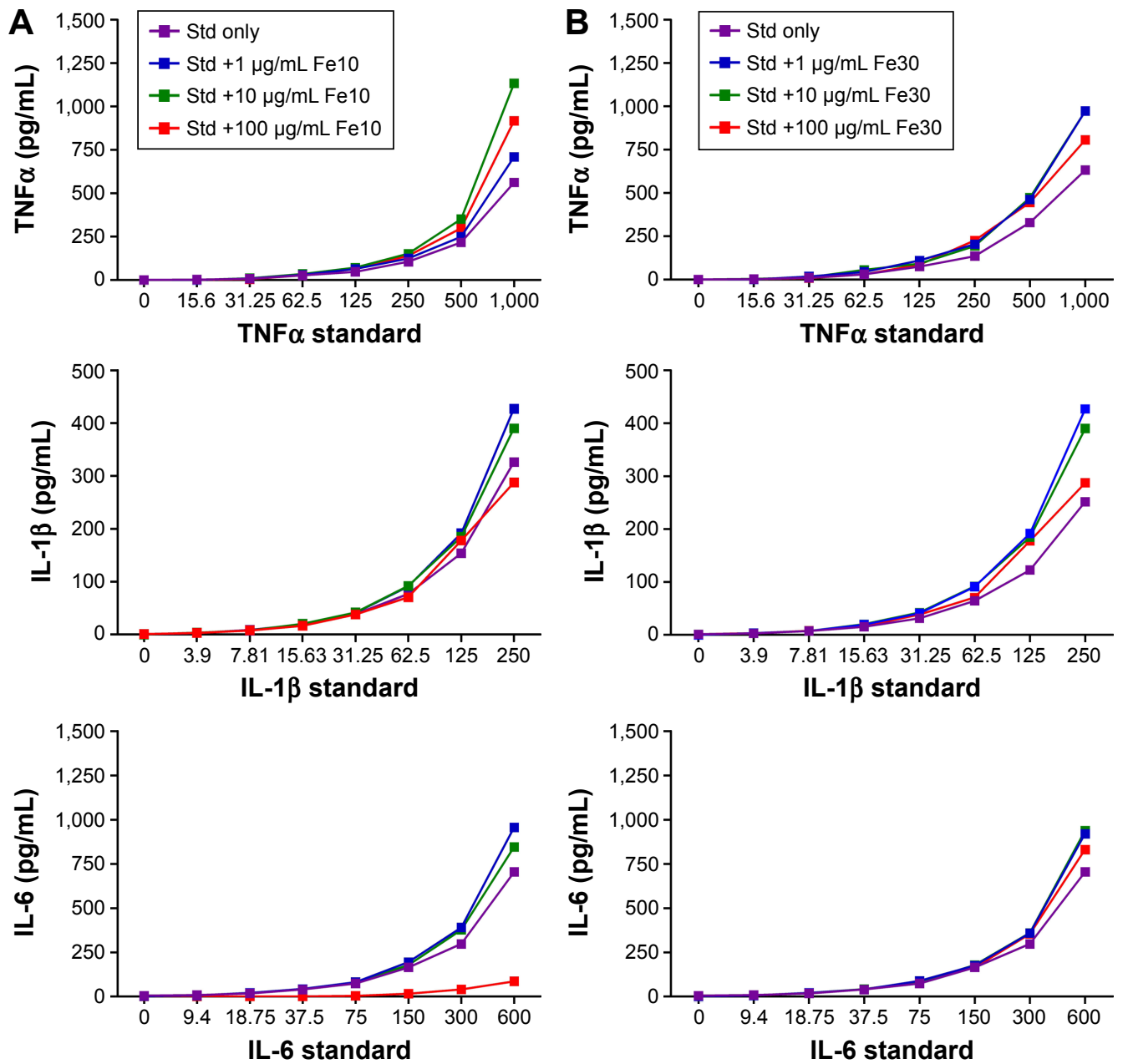

Figure S2 Cytokine adsorption to the IONPs.

Notes: Cell-free samples containing (A) $10 \mathrm{~nm}$ and (B) $30 \mathrm{~nm}$ IONPs (I $\mu \mathrm{g} / \mathrm{mL}, 10 \mu \mathrm{g} / \mathrm{mL}$, and $100 \mu \mathrm{g} / \mathrm{mL}$ ) were incubated with recombinant TNF $\alpha$, IL-I $\beta$, and IL-6, respectively, for 6 hours, and cytokine concentration in the supernatant was measured using ELISA. Results from one representative experiment are shown. Abbreviations: IONPs, iron oxide nanoparticles; TNF $\alpha$, tumor necrosis factor $\alpha$; IL, interleukin; ELISA, enzyme-linked immunosorbent assay; Std, standard. 

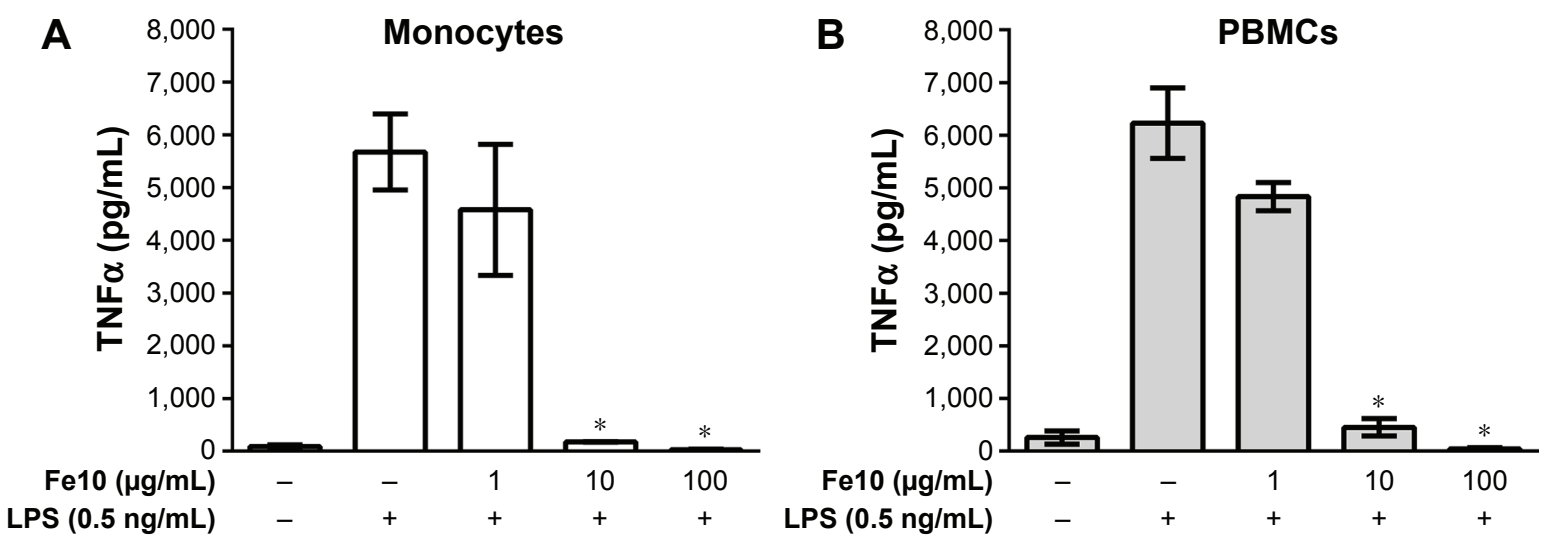

Figure S3 Cytokine response in IONPs-treated nonadherent monocytes and PBMCs in the presence of LPS.

Notes: (A) Nonadherent primary human monocytes and (B) PBMCs were treated with $10 \mathrm{~nm} I O N P s(1 \mu g / \mathrm{mL}, 10 \mu g / \mathrm{mL}$, and I00 $\mu \mathrm{g} / \mathrm{mL})$ and LPS (0.5 ng/mL) for $6 \mathrm{hours}$. The TNF $\alpha$ concentration released in the medium was measured using ELISA. Results are expressed as mean \pm SEM $(n=3)$. *Statistical significance $(P<0.05)$ compared to LPS alone.

Abbreviations: IONPs, iron oxide nanoparticles; PBMCs, peripheral blood mononuclear cells; LPS, lipopolysaccharide; TNF $\alpha$, tumor necrosis factor $\alpha$; ELISA, enzymelinked immunosorbent assay; SEM, standard error of the mean.
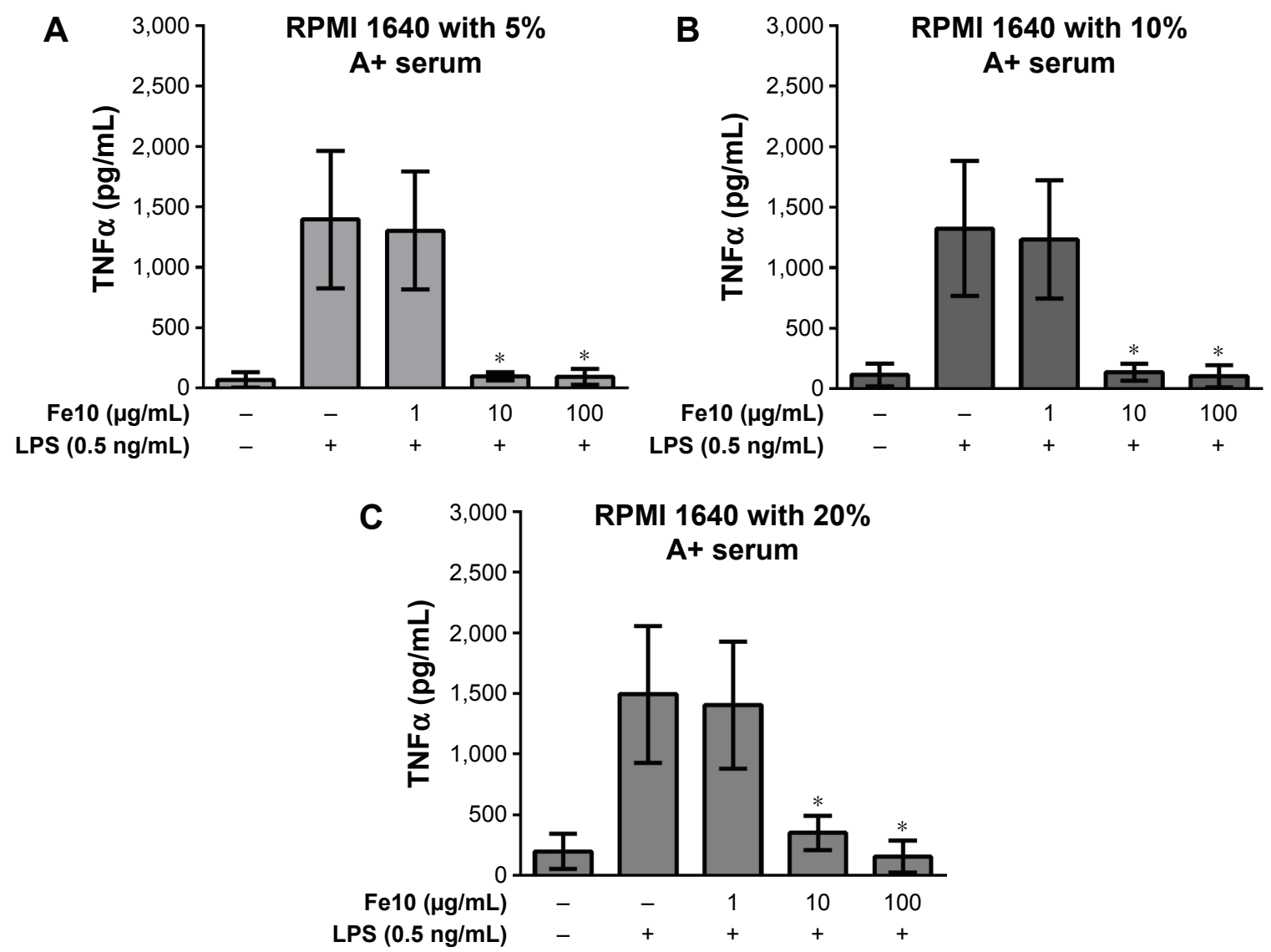

Figure S4 Influence of serum concentration in cell culture medium on cytokine response in IONPs-treated primary human monocytes in the presence of LPS.

Notes: The cells were treated with $10 \mathrm{~nm} 10 \mathrm{NPs}(1 \mu \mathrm{g} / \mathrm{mL}, 10 \mu \mathrm{g} / \mathrm{mL}$, and $100 \mu \mathrm{g} / \mathrm{mL})$ and LPS $(0.5 \mathrm{ng} / \mathrm{mL})$ for 6 hours in cell culture medium containing varying concentrations of A+ serum. (A) RPMI 1640 with $5 \%$ A+ serum. (B) RPMI 1640 with $10 \%$ A+ serum. (C) RPMI 1640 with $20 \%$ A+ serum. The TNF $\alpha$ concentration released in the medium was measured using ELISA. Results are expressed as mean \pm SEM $(n=3)$. *Statistical significance $(P<0.05)$ compared to LPS alone.

Abbreviations: IONPs, iron oxide nanoparticles; LPS, lipopolysaccharide; TNF $\alpha$, tumor necrosis factor $\alpha$; ELISA, enzyme-linked immunosorbent assay; SEM, standard error of the mean. 


\section{$\mathrm{Fe} 10100 \mu \mathrm{g} / \mathrm{mL}$}
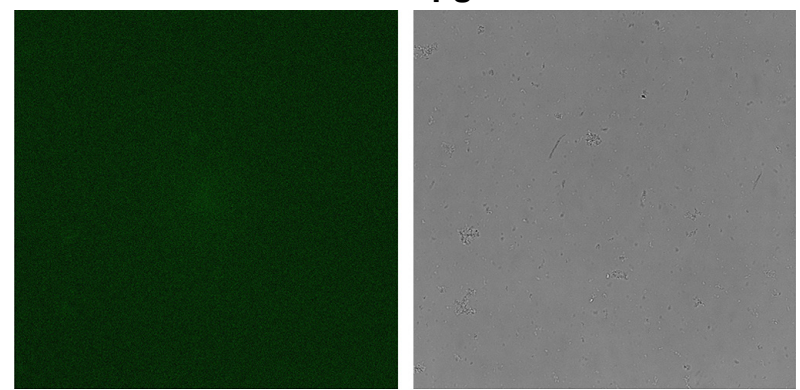

Pellet Fe10 $100 \mu \mathrm{g} / \mathrm{mL}$ LPS 100 ng/mL
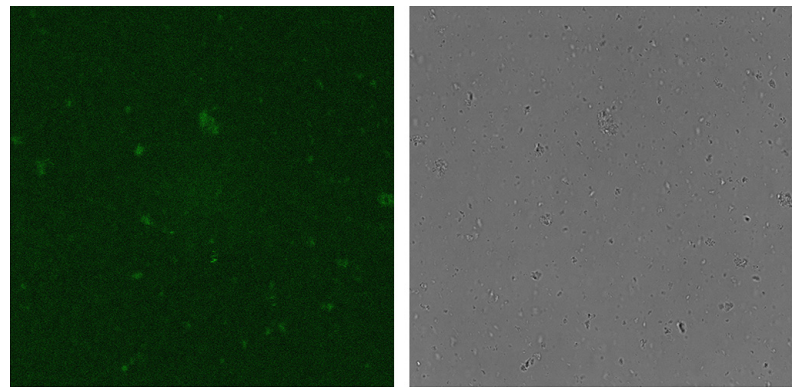

Pellet Fe10 $100 \mu \mathrm{g} / \mathrm{mL}$ LPS $500 \mathrm{ng} / \mathrm{mL}$
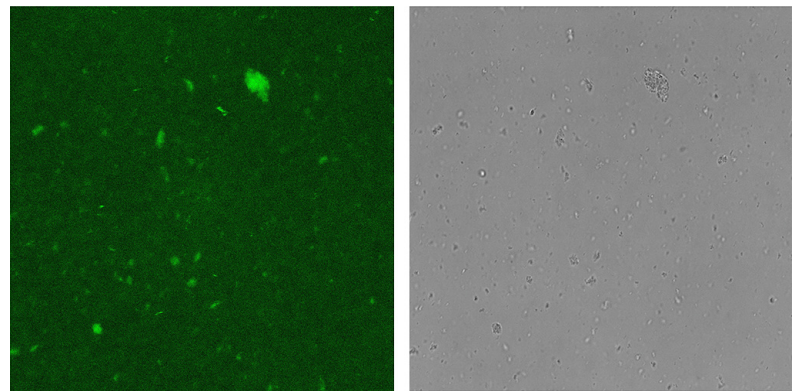

Figure S5 LPS adsorption to the IONPs.

Notes: Cell-free samples containing nanoparticles ( $100 \mu \mathrm{g} / \mathrm{mL})$ and LPS (100 ng/mL and $500 \mathrm{ng} / \mathrm{mL}$ in two different setups) were centrifuged at $15,000 \times \mathrm{g}$ for 2 hours $\left(4^{\circ} \mathrm{C}\right)$. The fluorescence intensity of the resuspended pellets was compared to a sample containing only nanoparticles $(100 \mu \mathrm{g} / \mathrm{mL})$. A representative image of each sample is shown.

Abbreviations: LPS, lipopolysaccharide; IONPs, iron oxide nanoparticles.

\section{Publish your work in this journal}

The International Journal of Nanomedicine is an international, peerreviewed journal focusing on the application of nanotechnology in diagnostics, therapeutics, and drug delivery systems throughout the biomedical field. This journal is indexed on PubMed Central, MedLine, CAS, SciSearch $\AA$, Current Contents $\AA^{\circledR} /$ Clinical Medicine,
Journal Citation Reports/Science Edition, EMBase, Scopus and the Elsevier Bibliographic databases. The manuscript management system is completely online and includes a very quick and fair peer-review system, which is all easy to use. Visit http://www.dovepress.com/ testimonials.php to read real quotes from published authors.

Submit your manuscript here: http://www.dovepress.com/international-journal-of-nanomedicine-journal 